\title{
Bioinspired multifunctional layered magnetic hybrid materials
}

Christian Debus MSC

PhD student, Department of Physical Chemistry, University of Konstanz, Konstanz, Germany (Orcid:0000-0003-1962-318X)

\section{Baohu Wu PhD}

Postdoctoral Fellow, Jülich Centre for Neutron Science, Heinz MaierLeibnitz Zentrum, Garching, Germany

Tina Kollmann MSC

PhD student, Computer Chemistry Centre, University Erlangen-Nuremberg, Erlangen, Germany

Patrick Duchstein PhD

Postdoctoral Fellow, Computer Chemistry Centre, University

Erlangen-Nuremberg, Erlangen, Germany (Orcid:0000-0002-9925-8639)

\section{Maria Siglreitmeier MSC}

PhD student, Department of Physical Chemistry, University of Konstanz, Konstanz, Germany

Steven Herrera BSC

PhD student, Materials Science and Engineering Program, University of California Riverside, Riverside, CA, USA

Dominik Benke MSC

PhD student, Department of Physical Chemistry I, University of Bayreuth, Bayreuth, Germany
David Kisailus PhD

Professor, Department of Chemical and Environmental Engineering and Materials Science and Engineering Program, University of California Riverside, Riverside, CA, USA (Orcid:0000-0001-9976-485X)

Dietmar Schwahn PhD

Senior Scientist, Jülich Centre for Neutron Science, Heinz Maier-Leibnitz Zentrum, Garching, Germany; Technische Universität München

Forschungs-Neutronenquelle Heinz Maier-Leibnitz, Garching, Germany (Orcid:0000-0003-2134-0138)

Vitaliy Pipich $\mathrm{PhD}$

Senior Scientist, Jülich Centre for Neutron Science, Heinz Maier-Leibnitz Zentrum, Garching, Germany

Damien Faivre PhD

Group Leader, Biosciences and Biotechnologies Institute, Aix Marseille Universite, CEA and CNRS, Saint-Paul-lès-Durance, France

(Orcid:0000-0001-6191-3389)

Dirk Zahn PhD

Professor, Computer Chemistry Centre, University Erlangen-Nuremberg, Erlangen, Germany

Helmut Cölfen PhD

Professor, Department of Physical Chemistry, University of Konstanz, Konstanz, Germany (corresponding author: helmut.coelfen@unikonstanz.de) (Orcid:0000-0002-1148-0308)

Nature has taken millennia to come up with unique solutions for providing materials with properties tailored toward versatile demands, making use of the very limited resources available in natural environments. Today, these biomaterials can be used as inspiration by combining and 'remixing' the concepts that nature displays to create new bioinspired materials. Here, the authors present materials combining the structural and functional elements of multiple biominerals: the inorganic-organic lamellar structure responsible for the high fracture toughness of nacre; highly mineralized composites, which give different mollusk teeth their very high hardness and strength; and the particle orientation and magnetic anisotropy of magnetosomes, giving magnetotactic bacteria a sensitive means to navigate along geomagnetic field lines. The authors show how the mechanical properties of a composite material can be improved with the addition of each of these elements. Small-angle neutron scattering studies and molecular simulation give additional insights into the mineralization from the very first attached ions to the finished composite.

\section{Notation}

$\mathrm{d} \Sigma / \mathrm{d} \Omega$ scattering cross section, the normalized scattering intensity

E modulus

$H$ hardness

I scattering intensity

$\boldsymbol{Q} \quad$ scattering vector

$Q_{\mathrm{c}} \quad$ scattering vector at the knee point

$R_{\mathrm{g}} \quad$ radius of gyration

$R_{\text {mean }}$ mean radius of the spheres

$\alpha \quad$ shape dimension parameter, $\alpha \approx 4(\alpha=-n$, where $n$ is the power law exponent)

$\theta \quad$ scattering angle

$\lambda$ neutron wavelength

$\phi \quad$ volume fraction

\section{Introduction}

Biominerals are remarkable for making the best out of the limited resources in natural environments. Often, a complex hierarchy of organic and inorganic components is used to create materials far surpassing the properties of their separate components. Today, materials copying the structural elements of natural biominerals can often surpass these biominerals regarding their mechanical properties. ${ }^{1}$ The ability to create such artificial materials with only the resources available to a living organism in a natural environment is still an impressive feature and rarely reported. ${ }^{2}$ One such material, which is very prominent and often copied in bioinspired material synthesis, is nacre. ${ }^{1-20}$ The clever combination of multiple mechanisms - for example, a layered structure with alternating organic and inorganic layers, leading to easier fracture dissipation leads to an increase in the fracture resistance in the material by a factor of 3000 compared to single-crystalline aragonite, which is the inorganic phase of nacre. ${ }^{21}$ Another interesting group of biominerals known particularly for their record holding hardness, abrasion resistance and tensile strength are the radular teeth of chitons and limpets. A fully mineralized chiton tooth consists of a hard outer shell and a softer inner core. The outer shell consists of rod-like magnetite $\left(\mathrm{Fe}_{3} \mathrm{O}_{4}\right)$ nanostructures embedded in a matrix of fibrous 
chitin. The material shows the highest stiffness and hardness in biominerals found to date. ${ }^{22}$ Magnetite is the main constituent of these outer shell regions (up to $98 \%$ ). ${ }^{23}$ The arrangement of the anisotropic magnetite rods in chitons also provides them with incredible wear resistance. ${ }^{24}$ The softer and less mineralized inner core consists of other iron (Fe)-based minerals and/or apatite. ${ }^{22,25} \mathrm{~A}$ combination of material selection and architecture is important for shock absorption and crack deflection, avoiding total failure of the teeth even under harsh conditions..$^{22,23,25,26}$ Here, differences in the elastic modulus between regions (e.g. core and shell, mineral and organic) can deflect crack propagation. ${ }^{27}$ For example, the magnetite shell of Cryptochiton stelleri, with the highest reported stiffness of any biological mineral, is directly adjacent to a much softer core of phosphosiderite. It displays clear crack deflection that enables significant damage tolerance. ${ }^{22}$ There is a junction zone between the core and shell in some other mollusks that is mineralized with lepidocrocite $^{26}$ and also promotes crack deflection. Furthermore, the organic scaffold used to template the growth of these iron-based minerals ends up enveloping the mineral, providing an additional layer of resistance for crack propagation and thus enabling significant toughening. ${ }^{28-30}$ The radular teeth of many limpets show a macroscopic structure similar to that of chiton teeth with a hard, highly mineralized iron oxide cusp and a softer core. ${ }^{31}$ In this case, the core is mineralized with silica $\left(\mathrm{SiO}_{2}\right)$ and the hard cusp consists of goethite in the form of high-aspect-ratio nanofibers. These are often embedded in an organic-inorganic composite with silica as the inorganic part. ${ }^{32}$ The goethite content of the cusp is only up to 80 wt.\%, and limpet teeth are observed to be softer than chiton teeth. Still, the nanofiber reinforcement leads to a tensile strength higher than that of spider silk, setting a new record for biological materials. ${ }^{33}$ Another species using iron oxide biomineralization, but for a completely different purpose, are magnetotactic bacteria. ${ }^{34}$ These organisms mineralize magnetite nanoparticles within special organelles called magnetosomes. With sizes usually in the ferrimagnetic single-domain size range, the particles show a high magnetic dipole moment. ${ }^{35}$ To maximize the dipole moment, the nanoparticles are arranged into chains through attachment to filament-like structures within the bacteria. ${ }^{36-38}$ In this way, the bacteria can use the magnetosomes as a way to navigate within the earth's magnetic field.

While the field of bioinspired mineralization and bioinspired materials is very widespread today, ${ }^{39-45}$ particularly in the case of nacre-templated layered materials, ${ }^{1-14}$ inspiration is seldom taken from more than one biomineral at once, ${ }^{15-17}$ although several biominerals are recognized to be multifunctional. ${ }^{46}$ The approach of this work is to pick out the elements of the aforementioned four biominerals and try to incorporate them into one new material.

The authors want to observe step by step how improvement of material properties can be achieved by the gradual addition of each feature. The ultimate goal would be to present a material which combines all the advantageous properties of its model materials by combining the structural features which make each of these biominerals unique.
Figure 1 schematically depicts the authors' synthetic route and details which steps are adopted from which biomineral (see also Appendix 1). The synthesis starts out with a porous, layered scaffold, either from demineralized nacre or from an artificial, freeze-cast chitin scaffold (1). ${ }^{2}$ The scaffold is infiltrated with a gelatin hydrogel, which aids in mineralization and keeps the pores open (2). This hydrogel is mineralized with magnetite, creating a material combining the layered nacre structure with a magnetite composite mimicking chiton tooth cusps (3). With magnetite nanoparticles in the ferrimagnetic size range, ordering into linear arrangements as seen in magnetotactic bacteria is possible (4). ${ }^{47}$ Finally, the mechanical properties can be improved by mineralizing with a second mineral phase, silica, taking inspiration from limpet tooth cusps (5).

In previous works, ${ }^{15-17}$ the authors have started to utilize the first steps of this concept and found that, indeed, the synthesis of the desired materials is feasible. As described in a previous publication by the authors, ${ }^{16}$ a synthesis was developed in which the mineralization of a hydrogel-filled natural scaffold led to a layered, nacre-like material. The platelets consisted of a chitontooth-inspired composite of magnetite particles embedded in gelatin. The synthesis involved demineralization of natural nacre, leaving behind a layered scaffold suitable for mineralization. Gelatin was infiltrated into the scaffold, mimicking the first steps in the biosynthesis of nacre and other biominerals, where the soft organic phase is created first and then mineralized. ${ }^{48}$ The first mineralization step was the infiltration of the hydrogel scaffold with iron (II) $\left(\mathrm{Fe}^{2+}\right)$ and iron (III) $\left(\mathrm{Fe}^{3+}\right)$ salts with the stoichiometry found in magnetite (1:2 iron (III)/iron (II)). The second step involved a rapid change in $\mathrm{pH}$ by placing the ironloaded gel in a basic solution. This leads to the precipitation of magnetite nanoparticles with size of around $10 \mathrm{~nm}$ (Figure 2). ${ }^{15} \mathrm{~A}$ degree of mineralization of up to $65 \mathrm{wt} . \%$ was achieved by repeating these steps up to six times. Further repetition did not

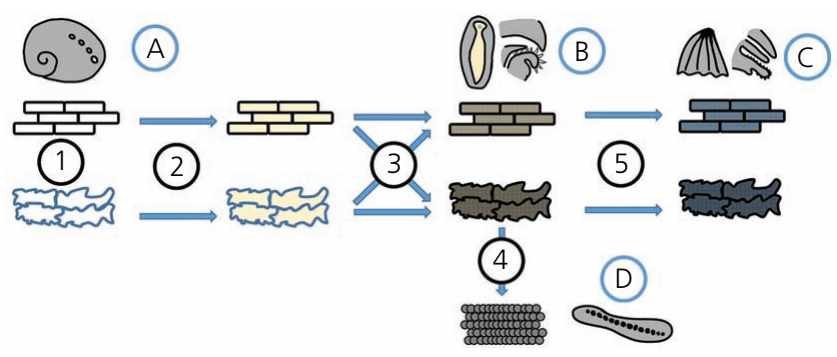

Figure 1. A porous, layered scaffold (1) is infiltrated with gelatin (2) and can consecutively be mineralized in multiple mineralization cycles to yield either a superparamagnetic or a ferrimagnetic

composite (3). The ferrimagnetic particles in these composites can be arranged linearly (4). In the second mineralization step, silica is introduced into the material (5). The model materials are denoted by letters: A, nacre from Haliotis laevigata; B, chiton radular teeth from Patella vulgata; C, limpet radular teeth from C. stelleri; $D$, magnetosome chains from magnetotactic bacteria 


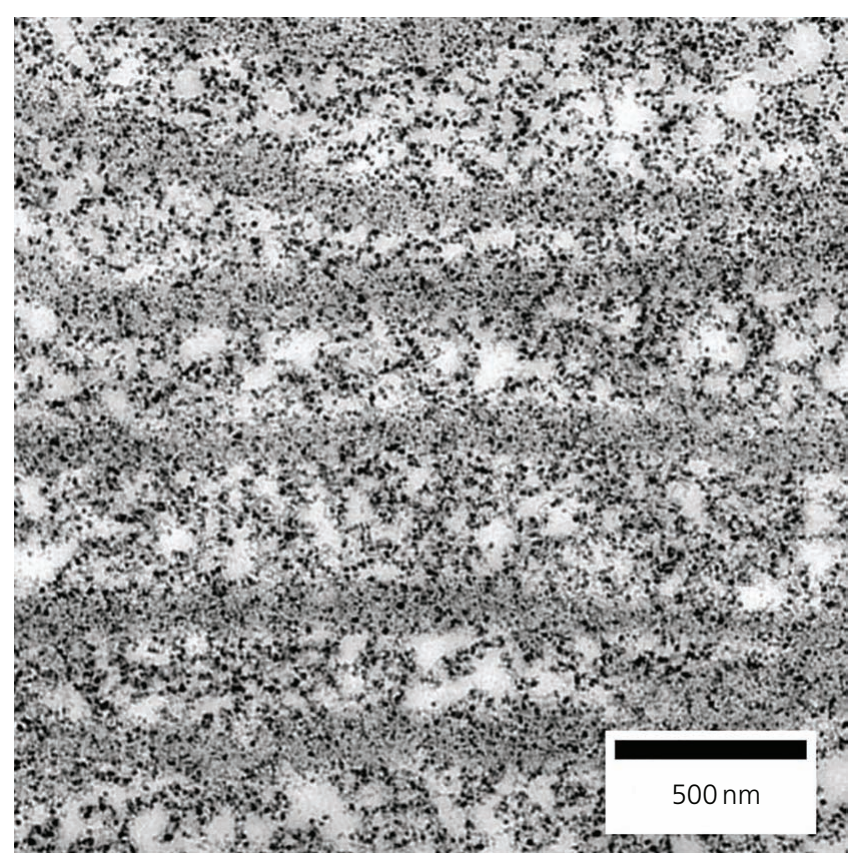

(a)

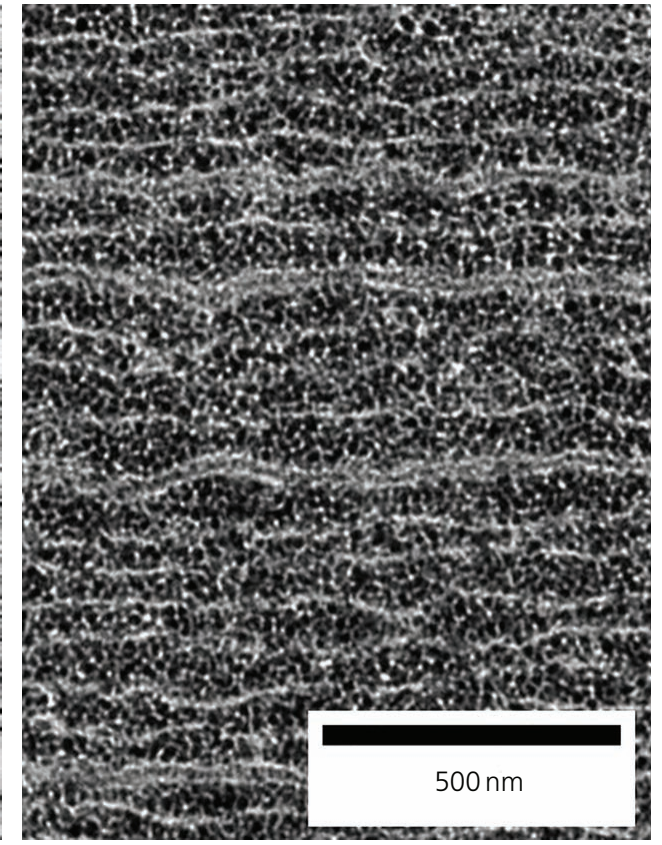

(b)

Figure 2. Transmission electron microscopy images of microtome cuts of (a) swollen and (b) dried layered superparamagnetic composites after six mineralization cycles. Due to the lower electron contrast of chitin compared to that of magnetite, the chitin layers appear as bright lines in (b)

lead to a notable increase in mineral content. In addition, molecular simulation studies showed how gelatin and chitin from the nacre scaffold can both act as nucleators for the magnetite particles. ${ }^{16}$ As expected for a particle size of around $10 \mathrm{~nm}$, the material showed a superparamagnetic behavior. Saturation magnetizations of $26 \mathrm{emu} / \mathrm{g}$ at $298 \mathrm{~K}$ and $36 \mathrm{emu} / \mathrm{g}$ at $2 \mathrm{~K}$ could be measured. ${ }^{16}$ Taking into account the degree of mineralization of around $65 \mathrm{wt} . \%$, these values are comparable to the saturation magnetization for pure particles found in literature. ${ }^{49}$

In the following sections, the authors want to take a closer look at this material, also addressing in particular the mechanical properties, which were not investigated before. The authors present variations and expansions of the aforementioned synthesis and observe the impact of structural changes on the material properties. This is accompanied by an in-depth analysis of the mineralization steps from first nucleation to particle growth by neutron scattering as well as molecular simulation studies (see Appendix 2, which also includes Tables 4-7).

\section{Results and discussion}

\subsection{Layered magnetite composites}

The material obtained after six cycles of magnetite mineralization was analyzed for its mechanical properties through nanoindentation. A hardness of $0.63 \mathrm{GPa}$ and a Young's modulus of $17.94 \mathrm{GPa}$ were determined (Table 1). The material does not yet match the hardness of $3 \cdot 13 \mathrm{GPa}$ and Young's modulus of $67 \cdot 2 \mathrm{GPa}$ measured for nacre from a Haliotis laevigata shell, but the mechanical properties are comparable to those, for example, of human dentin. ${ }^{50}$ Nonetheless, the layered structure was shown to have importance for the overall material performance as its incorporation led to an improvement in hardness and Young's modulus. The involvement of the layered scaffold compared to the plain mineralized gelatin ferrogels led to a doubling in hardness and an increase in stiffness by $\sim 130 \%$ (hardness of $0.31 \mathrm{GPa}$ and Young's modulus of $7.9 \mathrm{GPa}$ were determined for the plain ferrogel without nacre scaffold). In addition, mechanical anisotropy was introduced into the material, leading to better performance perpendicular to the platelets. Hardness and stiffness are 40 and 30\% lower when measuring parallel instead of perpendicular to the layers $(0.38$ and $12.63 \mathrm{GPa}$, respectively). This is an unexpected result since, usually, the hardness and stiffness are higher when measured parallel to the layers. $^{51,52}$ The limited degree of mineralization of only up to $65 \mathrm{wt} . \%$ was determined as the main obstacle for further improvement of the material, particularly when keeping in mind the high degrees of mineralization observed for many natural biominerals (e.g. $95 \%$ in nacre or $98 \%$ in the shell region of chiton teeth). ${ }^{23}$ With the authors' synthetic approach, no higher degree of magnetite mineralization could be achieved. To overcome this problem, the authors made use of a second mineral phase, which is more easily infiltrated into the gelatin, as discussed in a later section.

Contrast variation is a valuable tool for investigating multicomponent systems such as the authors' composite through small-angle neutron scattering (Sans). This technique allows independently exploring the 
Table 1. Nanoindentation results for different unsilicified ferrogels

\begin{tabular}{|c|c|c|c|c|}
\hline & $\begin{array}{l}\text { Hardness: } \\
\text { GPa }\end{array}$ & $\begin{array}{c}\text { Standard deviation: } \\
\text { GPa }\end{array}$ & $\begin{array}{c}\text { Young's modulus: } \\
\text { GPa }\end{array}$ & $\begin{array}{c}\text { Standard deviation: } \\
\text { GPa }\end{array}$ \\
\hline \multicolumn{5}{|c|}{ Superparamagnetic material } \\
\hline \multicolumn{5}{|l|}{ Gelatin ferrogels } \\
\hline Plain gelatin & 0.29 & 0.01 & $5 \cdot 18$ & $0 \cdot 11$ \\
\hline 65 wt. $\%$ magnetite $(10 \mathrm{~nm})$ & $0 \cdot 31$ & 0.01 & $7 \cdot 90$ & 0.08 \\
\hline \multicolumn{5}{|l|}{ Layered composites with nacre scaffold } \\
\hline $65 \mathrm{wt} . \%$ magnetite $(10 \mathrm{~nm})$ perpendicular to layers & 0.63 & 0.05 & $17 \cdot 94$ & 0.89 \\
\hline \multicolumn{5}{|c|}{ Ferrimagnetic materials } \\
\hline Gelatin ferrogels & & & & \\
\hline 50 wt. $\%$ magnetite $(50 \mathrm{~nm})$ & 0.33 & 0.01 & $5 \cdot 84$ & 0.09 \\
\hline 50 wt. $\%$ magnetite $(90 \mathrm{~nm})$ & $0 \cdot 32$ & 0.01 & $6 \cdot 62$ & 0.22 \\
\hline Oriented parallel to field & $0 \cdot 26$ & $0 \cdot 18$ & $7 \cdot 69$ & $5 \cdot 47$ \\
\hline Oriented perpendicular to field & $0 \cdot 36$ & 0.01 & $10 \cdot 06$ & 0.24 \\
\hline \multicolumn{5}{|l|}{ Layered composites with nacre scaffold } \\
\hline $45 \mathrm{wt} . \%$ magnetite $(50 \mathrm{~nm})$ perpendicular to layers & 0.51 & 0.03 & $12 \cdot 38$ & 0.88 \\
\hline 45 wt. $\%$ magnetite $(50 \mathrm{~nm})$ parallel to layers & $0 \cdot 32$ & 0.09 & $10 \cdot 19$ & $2 \cdot 47$ \\
\hline 45 wt. $\%$ magnetite $(90 \mathrm{~nm})$ & $0 \cdot 36$ & 0.05 & 8.92 & $1 \cdot 23$ \\
\hline
\end{tabular}

inorganic mineral structure and the organic component in biominerals and biomimetic materials. ${ }^{53-55}$ It allows for hiding selective components of a multicomponent material by repetition of the Sans measurement with differing water $\left(\mathrm{H}_{2} \mathrm{O}\right)$ /heavy water $\left(\mathrm{D}_{2} \mathrm{O}\right)$ ratios. In a typical Sans contrast variation measurement (Figure 3), Sans scattering of the gelatin in ferrogels (measured in pure heavy water) shows hardly any change in the gel structure (three-dimensional cage-like) besides an increase in triple-helical content, which probably originates from interaction with the iron (II)/iron (III) ions.

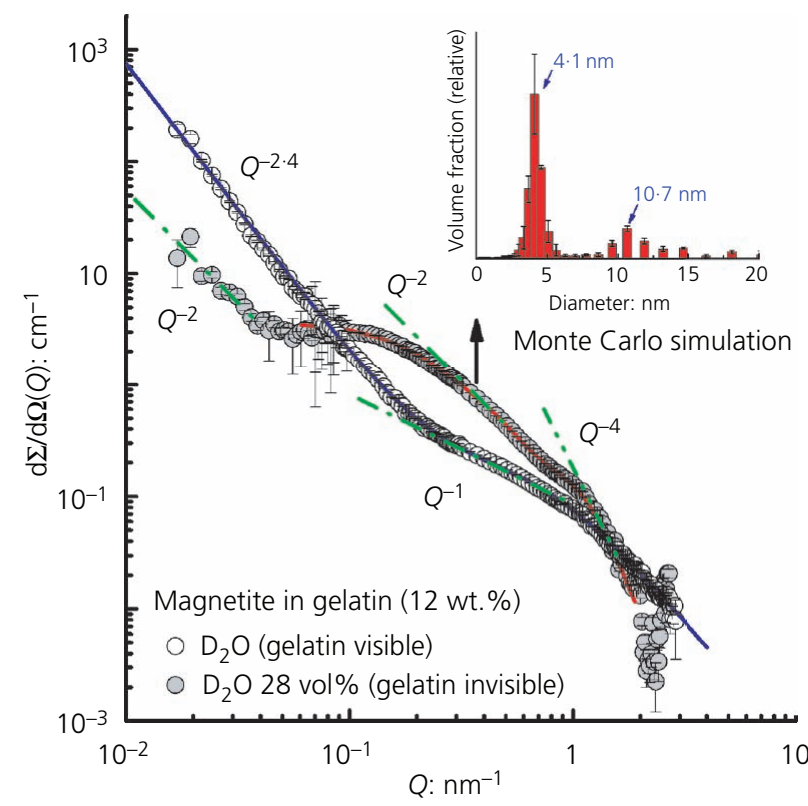

Figure 3. Sans measurements of a ferrogel with either the organic or the inorganic components hidden by contrast matching. The scattering patterns are fit with the Monte Carlo simulation method, ${ }^{56}$ resulting in the magnetite size distribution in the inset
In $28 \mathrm{vol} \%$ of heavy water, scattering from gelatin is suppressed and the magnetite nanoparticles are visualized. The obtained magnetite particle size distribution from the scattering curve appears consistent with the transmission electron microscopy (TEM) measurements (larger particle sizes of $\sim 10.7 \mathrm{~nm}$ coexist with smaller particles of $\sim 4 \cdot 1 \mathrm{~nm}$ ). The magnetite scattering also reveals slight correlation between the magnetite particles, which is even more pronounced in small-angle X-ray scattering experiments. Further, in the presence of the nacre scaffold, the fiber-like chitin structure helps with the formation of linearly aligned magnetite nanoparticles. ${ }^{16}$

\subsection{Ferrimagnetic layered composites}

To be able to write magnetic information into a material, the magnetite particles involved need sizes above the size limit for stable single magnetic domain particles $(>30 \mathrm{~nm})$. The adaptation of a synthesis by Sugimoto and Matijevic ${ }^{57}$ to the authors' system allows for materials containing particles with sizes adjustable between 50 and $90 \mathrm{~nm}$ (Figure 4), showing ferrimagnetic properties. Incorporation of the gelatin network into the large magnetic particles could be confirmed by Sans (see the online supplementary material). This synthesis involves infiltration with iron (II) sulfate $\left(\mathrm{FeSO}_{4}\right)$ instead of iron (II) chloride $\left(\mathrm{FeCl}_{2}\right)$ /iron (III) chloride $\left(\mathrm{FeCl}_{3}\right)$ and subsequent partial oxidation of the iron (II) to magnetite using a basic solution with potassium nitrate $\left(\mathrm{KNO}_{3}\right)$ as oxidizing agent. Variation in the iron (II) sulfate concentration from 0.2 to $0.3 \mathrm{M}$ varies the particle size between 50 and $90 \mathrm{~nm}$. The degree of mineralization can again be increased with each cumulative mineralization step. This synthesis does not reach the degree of mineralization seen for the superparamagnetic materials but still yields materials with up to $45 \mathrm{wt} \%$ magnetite content. Superconducting quantum interference device (Squid) measurements show the presence of magnetic hysteresis at 2 and $298 \mathrm{~K}$ as expected for a ferrimagnetic material. Mean values for saturation magnetization of $74 \mathrm{emu} / \mathrm{g}$ for $2 \mathrm{~K}$ and $67 \mathrm{emu} / \mathrm{g}$ for $298 \mathrm{~K}$ could be determined. 
Bioinspired, Biomimetic and Nanobiomaterials Volume 8 Issue BBN1
Bioinspired multifunctional layered

magnetic hybrid materials

Debus, Wu, Kollmann et al.

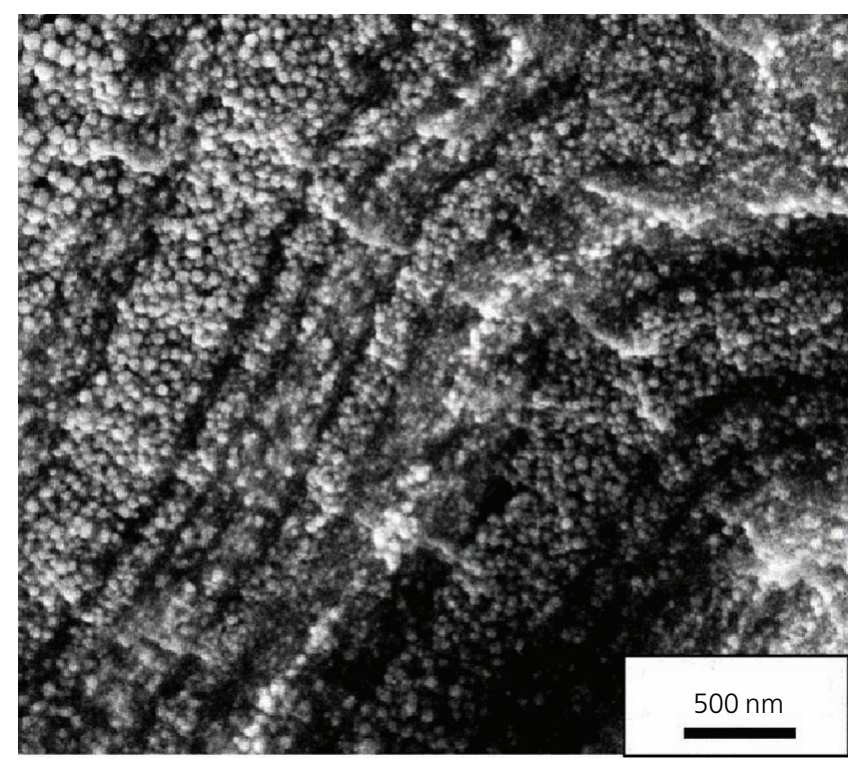

(a)

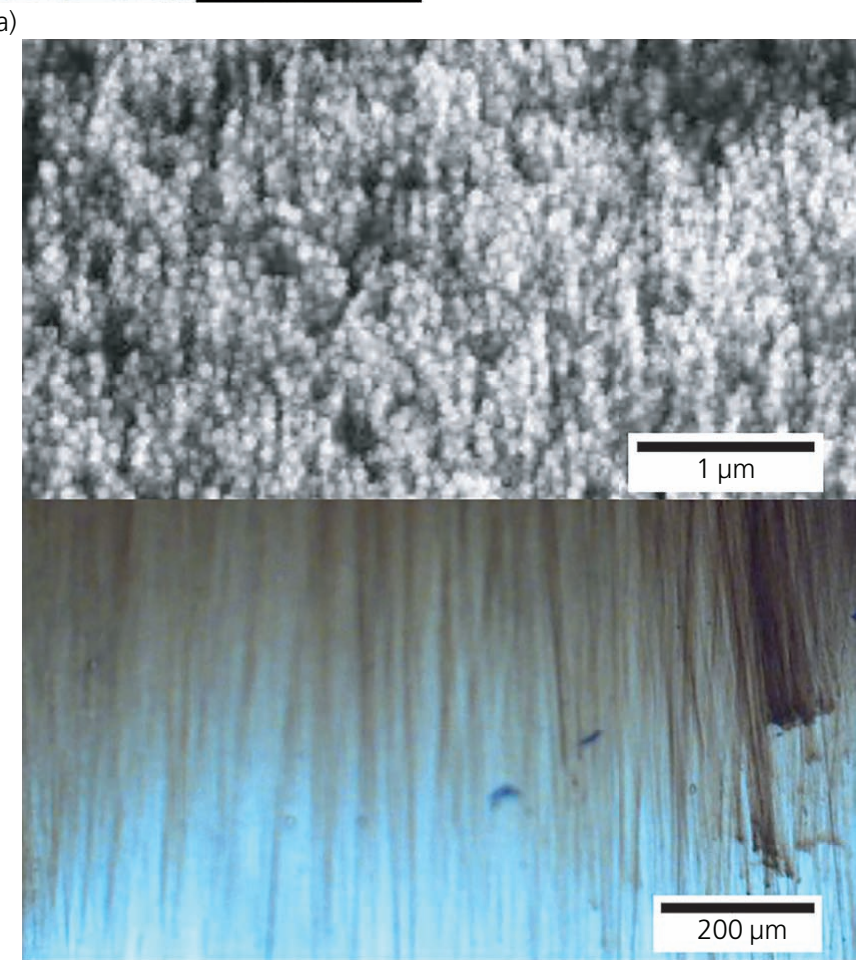

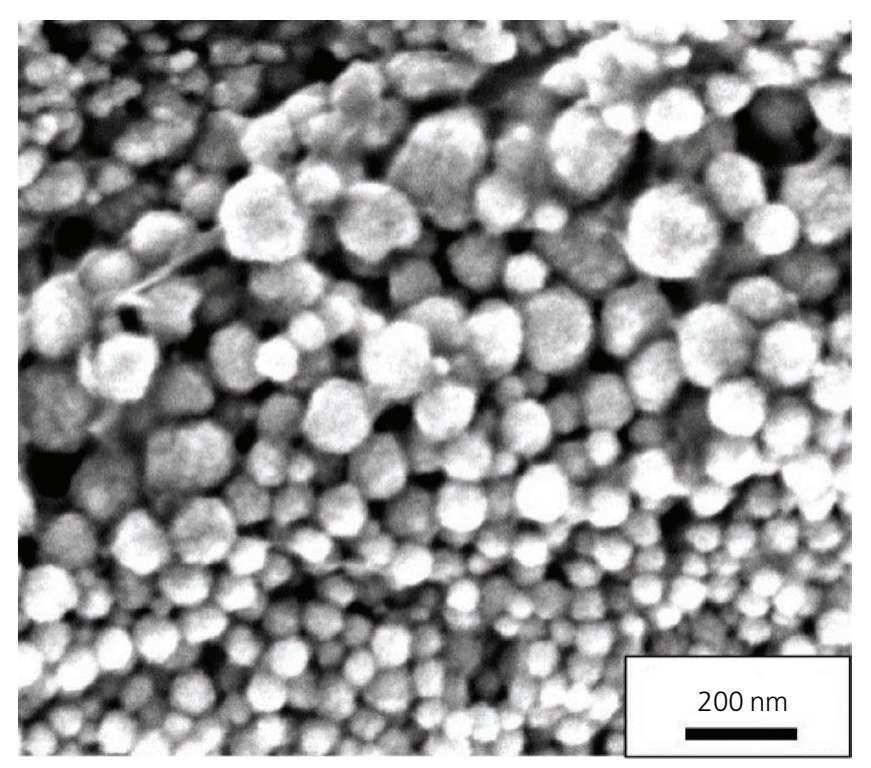

(b)

(c)

Figure 4. (a, b) Scanning electron microscopy (SEM) images of a cross-section through a layered composite synthesized with $0 \cdot 3 \mathrm{M}$ iron (II) sulfate at different magnifications; (c) SEM image (top) and light microscopic image (bottom), showing the arrangement into fibers on multiple length scales when samples are dried in a magnetic field

Evaluation of mechanical properties by nanoindentation shows that the material is softer and less stiff than the superparamagnetic material, probably due to better packing of the more monodisperse, smaller particles in the latter. Hardness of $0.51 \mathrm{GPa}$ and a Young's modulus of $12.38 \mathrm{GPa}$ could be achieved for $50 \mathrm{~nm}$ particles (Table 1), again putting the material into the same range as dentin or human bone.
Drying in a magnetic field introduces observable magnetic as well as mechanical anisotropy to the material. Light and electron microscopy show the formation of fibers on different length scales (Figure 4(c)). The linear particle arrangement leads to a coupling of the magnetic moments analogous to what is observed in magnetotactic bacteria. This increases, for example, the saturation magnetization along the axis of orientation as observable by Squid. ${ }^{47}$ The orientation also 
Bioinspired, Biomimetic and Nanobiomaterials Volume 8 Issue BBN1
Bioinspired multifunctional layered

magnetic hybrid materials

Debus, Wu, Kollmann et al.

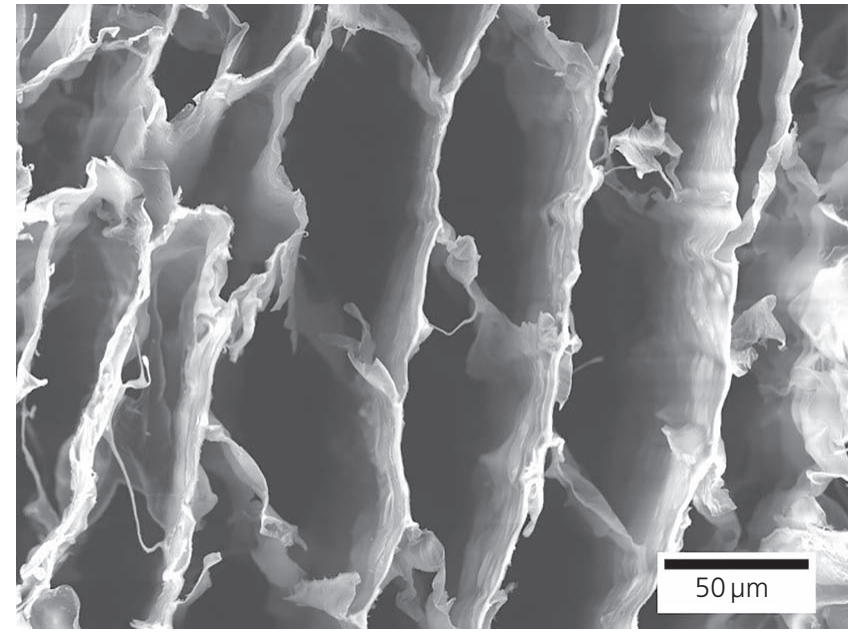

Figure 5. Scanning electron microscopy image of a freeze-cast chitin scaffold

leads to anisotropic mechanical properties. As such, hardness was increased by a factor of $20 \%$, while Young's modulus increased by about $50 \%$ perpendicular to the axis of orientation as compared to the unoriented material (hardness of $0.36 \mathrm{GPa}$ and Young's modulus of $10.06 \mathrm{GPa}$ ). Indentations parallel to the axis show high standard deviations, with the average hardness slightly dropping by $20 \%$, but again Young's modulus increased by about $15 \%$.

\subsection{Freeze-cast chitin scaffolds for upscaling}

The use of nacre as a natural scaffold source limits the possible shape and size of the synthesized materials. To investigate the potential for upscaling, the authors created porous chitin scaffolds by freeze-casting. These have already successfully been used in the past to create artificial nacre from natural components. ${ }^{2}$ Chitin is also known to be an essential constituent of the natural nacre scaffold. $^{58,59}$ Starting from acidic chitosan solutions, porous scaffolds can be created by unidirectional freezing followed by freeze-casting (Figure 5).

Such chitosan scaffolds can then be acetylated to chitin with acetanhydride. Vacuum infiltration of gelatin allows for the fabrication of hybrid scaffold materials in analogy to the nacre-gelatin hybrids described earlier. ${ }^{16}$ These materials can be mineralized in analogy to the previously described procedures for nacre-based materials, giving superparamagnetic and ferrimagnetic layered materials. These have a larger layer thickness than in nacre due to scaffold pores of approximately $50 \mu \mathrm{m}$ after freeze-drying (Figure 5) and 10-20 $\mu \mathrm{m}$ in the dried materials (Figure 6(a)). The layer thickness in such freeze-cast materials can be influenced by controlling solute concentration, additives and the freezing speed. ${ }^{60}$ The layer thickness was chosen as small as possible by direct freezing with liquid nitrogen as coolant. The achievable degree of mineralization in these materials is comparable with those of the nacre-based materials. Whereas the superparamagnetic material matches the nacre material with a content of up to $65 \%$ magnetite, the ferrimagnetic material still achieves a mineral content of up to $52 \%$ as determined by thermogravimetric analysis (TGA). Hardness and Young's modulus values of 0.59 and $9.8 \mathrm{GPa}$, respectively, were measured for the superparamagnetic material using nanoindentation. The ferrimagnetic material showed values of 0.48 and 10.4 GPa (compare with Table 2). The improved mechanical properties of the nacre-templated materials are possibly caused by the difference in layer thickness. A nanoindent may penetrate multiple layers in the nacre materials, while this is not the case for the materials based on freeze-cast scaffolds. However, an advantage of the materials using freeze-cast scaffolds is the possibility of upscaling with a larger possible size.

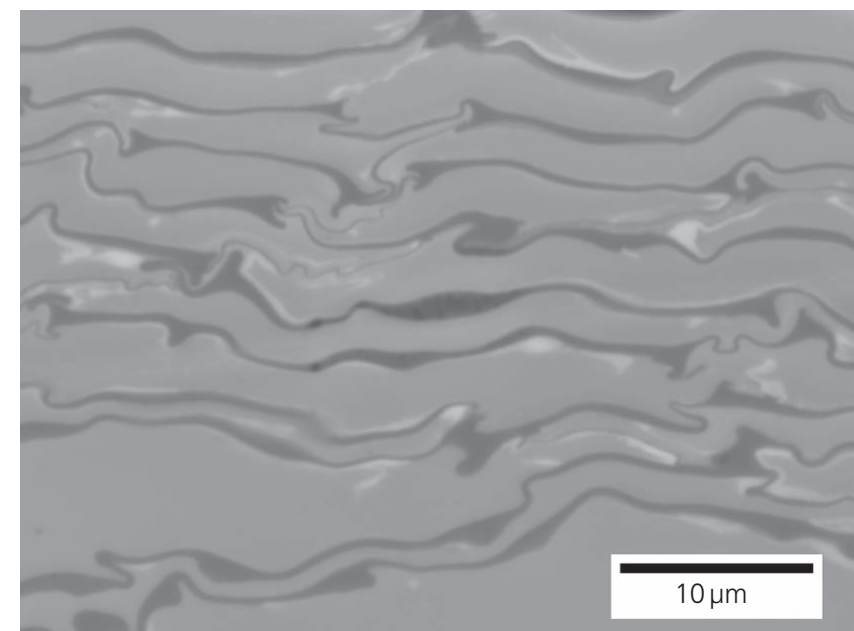

(a)

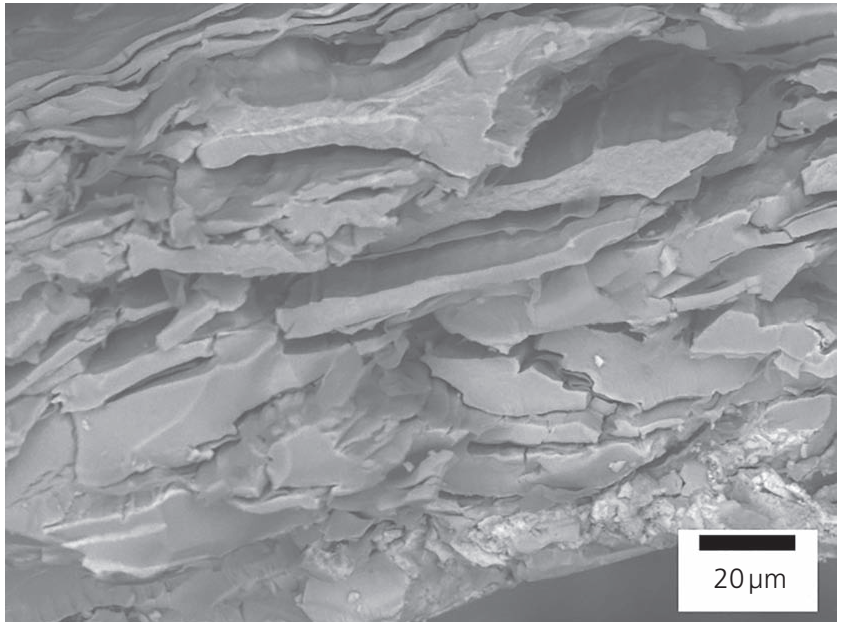

(b)

Figure 6. (a) Backscattered-electron scanning electron micrograph of the polished surface of a chitin-based magnetite-gelatin composite, showing the distorted layered internal structure; (b) fracture surface of the same material after silicification 
Table 2. Nanoindentation results from polished surfaces of pressed composites without silicification and after silicification

\begin{tabular}{|c|c|c|c|c|}
\hline & Hardness: GPa & Standard deviation: GPa & Young's modulus: GPa & Standard deviation: GPa \\
\hline \multicolumn{5}{|c|}{ Superparamagnetic material } \\
\hline \multicolumn{5}{|l|}{ Nacre-based } \\
\hline No silicon & 0.83 & 0.05 & $14 \cdot 7$ & $1 \cdot 0$ \\
\hline Milli-Q & $1 \cdot 22$ & $0 \cdot 12$ & $17 \cdot 4$ & $1 \cdot 7$ \\
\hline $10 \mathrm{mM}$ iron (III) chloride & 0.94 & 0.05 & $15 \cdot 4$ & 0.7 \\
\hline $100 \mathrm{mM}$ iron (III) chloride & $1 \cdot 21$ & 0.07 & $20 \cdot 4$ & $1 \cdot 1$ \\
\hline \multicolumn{5}{|l|}{ Chitin-based } \\
\hline No silicon & 0.59 & 0.02 & $9 \cdot 8$ & $0 \cdot 6$ \\
\hline Milli-Q & 1.96 & 0.09 & $22 \cdot 6$ & 0.9 \\
\hline $10 \mathrm{mM}$ iron (III) chloride & 1.46 & $0 \cdot 14$ & $23 \cdot 4$ & $1 \cdot 7$ \\
\hline $100 \mathrm{mM}$ iron (III) chloride & $1 \cdot 58$ & $\begin{array}{l}0.14 \\
\text { Ferrimagnetic mater }\end{array}$ & $20 \cdot 8$ & $1 \cdot 8$ \\
\hline Nacre-based & & & & \\
\hline No silicon & $0 \cdot 78$ & 0.04 & $14 \cdot 6$ & 0.6 \\
\hline $10 \mathrm{mM}$ iron (III) chloride & $1 \cdot 31$ & $0 \cdot 12$ & $18 \cdot 5$ & $0 \cdot 8$ \\
\hline $100 \mathrm{mM}$ iron (III) chloride & 0.98 & 0.04 & $18 \cdot 7$ & 0.9 \\
\hline
\end{tabular}

\subsection{Molecular simulations of magnetite mineralization}

To obtain molecular scale insights into iron oxide mineralization in the presence of collagen, the authors performed molecular simulation studies of $\mathrm{Fe}^{2+}(\mathrm{OH})_{2}$ and $\mathrm{Fe}^{3+}(\mathrm{OH})_{3}$ ion cluster association with a triple-helical (Gly-Hyp-Pro) ${ }_{n}$ polypeptide. Using the Kawska-Zahn approach, the authors studied the docking and subsequent relaxation of $\mathrm{Fe}^{\mathrm{II}}$ and $\mathrm{Fe}^{\mathrm{III}}$ species in water at a 1:1 ratio. ${ }^{61}$ To allow direct comparison, the collagen and the simulation method are chosen analogous to earlier studies on calcium and phosphate ion association with collagen. ${ }^{62}$ While $\mathrm{Fe}^{2+}(\mathrm{OH})_{2}$ and $\mathrm{Fe}^{3+}(\mathrm{OH})_{3}$ reflect predominant species in bulk water, the precipitated iron hydroxide may undergo proton transfer reactions upon association with collagen. This type of ripening reactions was recently incorporated into the authors' aggregation scheme on the basis of a combined quantum mechanical/molecular mechanics (QM/MM) approach. ${ }^{63}$ Thus, the authors' simulation protocol explicitly considers the ripening of iron hydroxide clusters to iron oxide $\left(+\mathrm{H}_{2} \mathrm{O}\right)$ as part of the relaxation process (see the online supplementary material for details on the molecular simulation models).

Similar to the authors' previous work on calcium phosphate association with collagen, it was also observed that iron clusters bind through hydrogen bonds and over salt bridges to the collagen surface without destroying the triple-helical structure of the polypeptide model. Upon precipitation of several clusters, the iron hydroxide aggregates reorganize in favor of tetrahedral and octahedral motifs. This already hints at the magnetite crystal structure, in which the iron atoms are tetrahedrally/octahedrally coordinated by oxygen ions. In cases where there are not enough hydroxide ions to complete the tetrahedral or octahedral coordination structure, salt bridges to oxygen atoms of the protein and to surrounding water molecules are observed.

Figure 7 shows the collagen model after 100 docking attempts. The precipitate comprises 29 iron (III), 24 iron (II), 122 hydroxide $\left(\mathrm{OH}^{-}\right)$and four superoxide $\left(\mathrm{O}^{2-}\right)$ ions. At this early stage of precipitation, the octahedral coordination motifs (highlighted in blue) clearly outnumber tetrahedral (yellow) ion clusters. Indeed, some of the tetrahedral $\left[\mathrm{Fe}^{3+}(\mathrm{OH})_{3} \mathrm{H}_{2} \mathrm{O}\right]$ clusters are reorganized in favor of octahedral motifs upon incorporation into the precipitate.

However, such disfavoring of tetrahedral motifs stands in contrast with the rearrangement observed in the course of proton transfer reactions. Ripening reactions leading to superoxide ions were found to depend on dissimilar coordination scenarios of two nearby hydroxide ions. While the proton-accepting hydroxide ions are weakly coordinated by iron ions, donating the proton from a hydroxide ion requires that the resulting oxygen ion be incorporated into the iron hydroxide cluster after structural relaxation (Figure 7, left). Strikingly, all of the observed superoxide ion formation events lead to the stabilization of conjugated tetrahedral-octahedral motifs. (The authors note, though, that a total of only four reaction events do not allow the formulation of a rigorous rule.)

\subsection{Silica as a filler mineral}

One limiting factor for the further improvement of the mechanical properties of the materials presented so far is the limited degree of mineralization of only up to $65 \%$. Therefore, a second mineral phase that can more easily infiltrated was added to act as a filler. Nature also shows concepts of organic matrices mineralized with multiple mineral species at the same time - for example, limpet teeth. Inspired by this, a mineralization process was developed to mineralize gelatin and gelatin-based ferrogels. Tetraethyl orthosilicate (Teos) is used as the organic silica precursor. The ferrogel/composite for subsequent silica mineralization is prepared by infiltration with $75 \%$ ethanol $(\mathrm{EtOH})$. Then, it is placed in a solution of $67 \cdot 5 \% \mathrm{EtOH}, 7 \cdot 5 \%$ prehydrolyzed Teos and $25 \%$ water.

Teos mineralization leads to a silica gradient within the material due to the slow diffusion into the gel and local differences in, for example, iron ion/magnetite particle concentrations and $\mathrm{pH}$. 


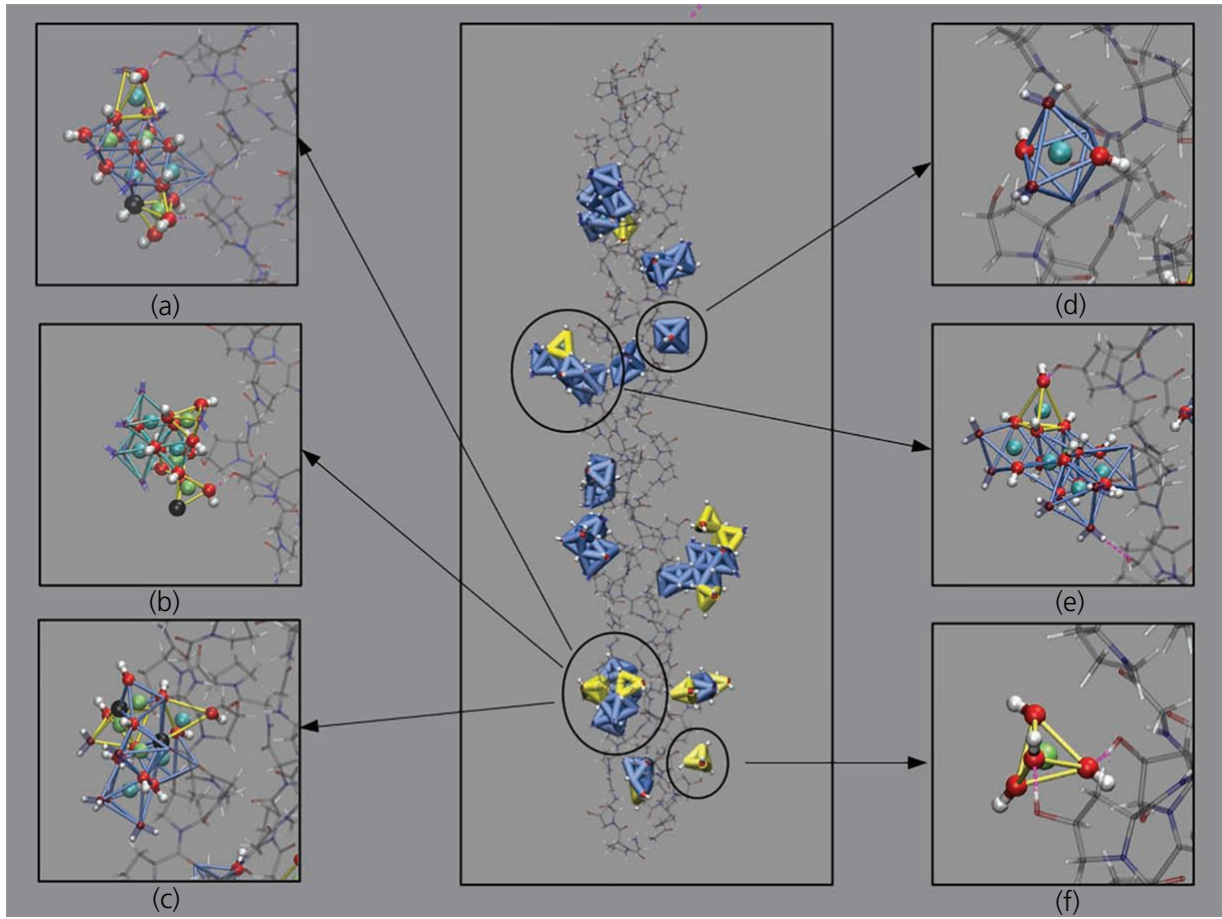

Figure 7. Final configuration of the authors' collagen triple-helix model after 100 iron hydroxide association and ripening attempts. The ripening in favor of superoxide ions is highlighted in (a)-(c), while (d)-(f) show the association of iron hydroxide. The latter involve (d) octahedral Fe" $(\mathrm{OH})_{2}$ complexes (including water molecules and oxygen ions from the collagen to complete the octahedral geometry), (f) tetrahedral Fe"I $(\mathrm{OH})_{3}$ complexes and (e) assemblies thereof. The ripening from iron hydroxide to iron oxide requires aggregation of several iron hydroxide clusters and then occurs stepwise in (a)-(c) upon considerable structural reorganization to accommodate the newly formed oxo ions. Colors: green, iron (III); cyan, iron (II); black, superoxide; red-white, hydroxide. Octahedral motifs are indicated by blue lines, whereas tetrahedral coordination is indicated by yellow lines

Shrinkage during drying would thus lead to tension in the material, resulting in fractures within the material. This problem is circumvented by lyophilization. The highly porous freeze-dried material can then be pressed into a compact pellet with a hydraulic press and a pressure of $300 \mathrm{MPa}$ (see cross-section in Figure 6). Pressing was also shown before to improve the mechanical properties of bioinspired composite materials. ${ }^{2} \mathrm{X}$-ray diffraction (XRD) measurements still show magnetite as the sole crystalline mineral phase after the silicification reaction (Figure S1(a) in the online supplementary material). Infrared measurements further show the formation of silica (Figure S1(b) in the online supplementary material).

To get deeper insight into the silicification process, each step of the mineralization was investigated with Sans. First, the structure of the gelatin hydrogel networks in the presence of EtOH was determined by Sans at room temperature. In Figure 8(a), the Sans diffractometers deliver scattering data from very small values of the scattering vector $Q$ (absolute value of $Q=4 \pi \sin \theta / \lambda$; $\theta$ is the scattering angle, and $\lambda$ is the neutron wavelength) on the order of $10^{-2}$ up to $3 \mathrm{~nm}^{-1}$.

The scattering curve of gelatin hydrogels with $75 \%$ of EtOH could be divided into two regimes separated by the so-called knee point at $Q_{\mathrm{c}} \approx 0.9 \mathrm{~nm}^{-1}$. The scattering profile below $Q=0.9 \mathrm{~nm}^{-1}$ within 'regime I' shows Guinier scattering of a colloid-like gelatin structure. This scattering is well described by the red solid line representing the fit of the data using the Schulz spheres model ${ }^{64}$ with a mean radius of $R_{\text {mean }} \approx 15 \cdot 3 \mathrm{~nm}$ and dimension $\alpha$ $\approx 4$. The fitting result shows that the colloid-like particles in the hydrogels have a dense inner spherical core and a smooth surface. The scattering curve above $Q=0.9 \mathrm{~nm}^{-1}$ within 'regime II' follows a power-law exponent of $1 \cdot 2$, indicating the rod-like structure of gelatin triple-helix bundles. A possible model structure sketch of a mixture of gelatin hydrogel $/ 75 \% \mathrm{EtOH}$ is shown in the right inset of Figure 8(a). Thereby for gelatin hydrogels in the presence of $75 \%$ of $\mathrm{EtOH}$, the scattering indicates domination of a rod-like structure of gelatin helix bundle network in coexistence with dense particle-like gelatin aggregates. In contrast, gelatin hydrogels in water reveal a significant difference in the small- $Q$ structure of large aggregates with a diameter of more than $280 \mathrm{~nm}$ (see the left inset sketch of Figure 8(a)).

Figure 8(b) shows Sans measurements of $7 \mathrm{wt} \%$ gelatin in an aqueous mixture of water and $\mathrm{EtOH}$ in prehydrolyzed Teos $\left(\mathrm{Teos} \cdot 4 \mathrm{H}_{2} \mathrm{O}\right)$. Sans results indicate that gelatin hydrogels in the presence of prehydrolyzed Teos without EtOH exhibit the same 


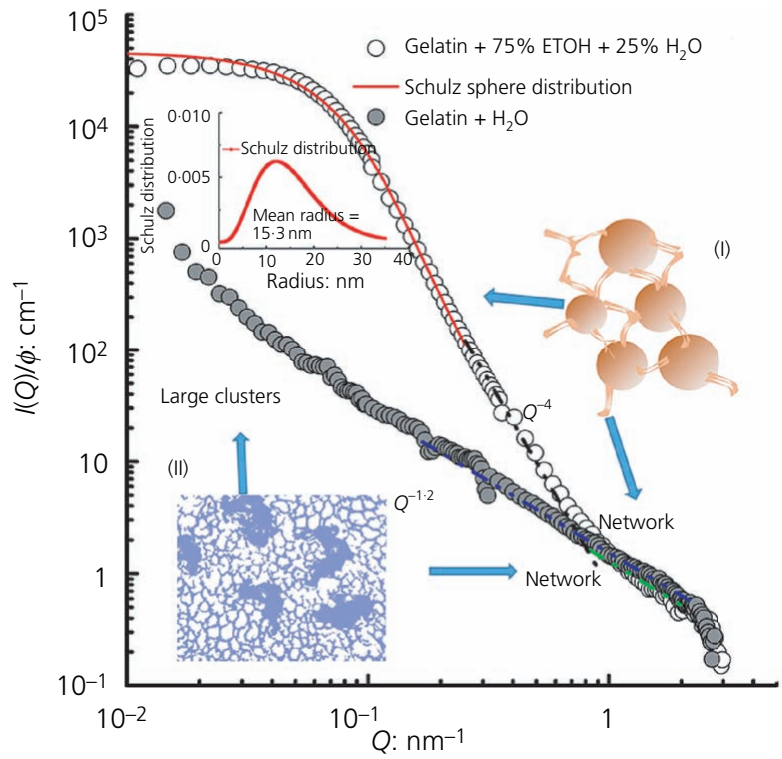

(a)

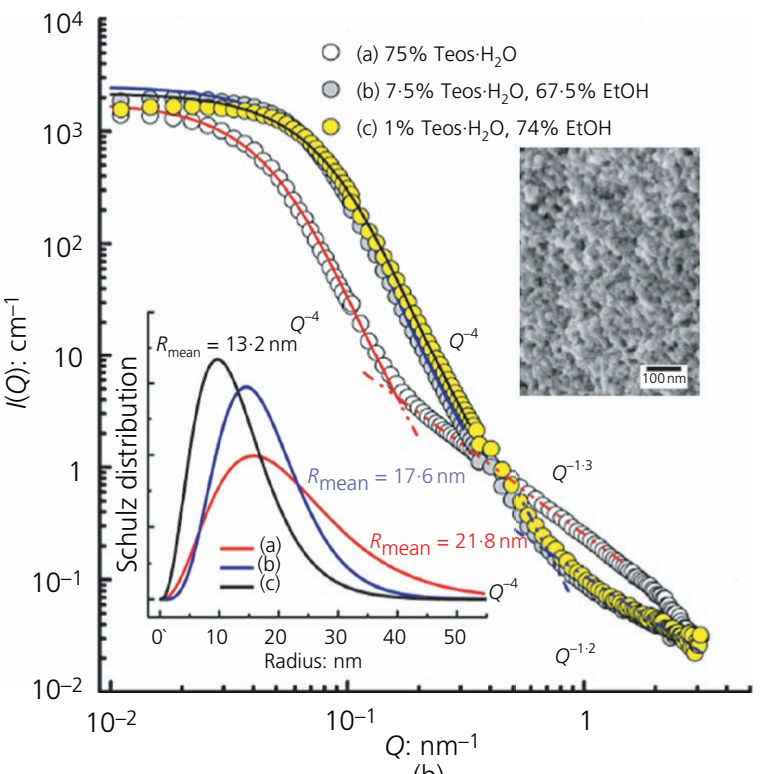

(b)

Figure 8. (a) Sans-Vsans (very small-angle neutron scattering) scattered intensity against scattering vector $\mathbf{Q}$ for gelatin hydrogels in the presence of $75 \% \mathrm{EtOH} / 25 \%$ water and water. The red solid line represents fitting by a sphere model with a Schulz size distribution. ${ }^{64}$ (b) Sans scattered intensity against scattering vector $\boldsymbol{Q}$ for gelatin hydrogels in the presence of $0-74 \% \mathrm{EtOH} / 25 \%$ water and prehydrolyzed Teos $\left(\mathrm{Teos} \cdot 4 \mathrm{H}_{2} \mathrm{O}\right.$ ). The solid line represents fitting by a sphere model with a Schulz size distribution. ${ }^{64}$ Inset: scanning electron microscopy image of gelatin mineralized with $75 \%$ prehydrolyzed Teos $/ 25 \%$ water

structure as the gelatin hydrogels in water. The scattering curves change significantly with EtOH in the hydrogels. The $Q_{\mathrm{c}}$ shifts to a higher value, indicating a smaller cage size of the gel network. Fitting results show that the radius of gelatin aggregates decreased from $21 \cdot 8$ to $13 \cdot 2 \mathrm{~nm}$ with increasing volume fraction of EtOH.
The Sans data agree with a scanning electron microscopy (SEM) image of the structure (inset in Figure 8(b)).

In Figure 9(a), the same sample placed into $75 \%$ prehydrolyzed Teos solution was measured again by Sans after $1 \mathrm{~d}$. Sans

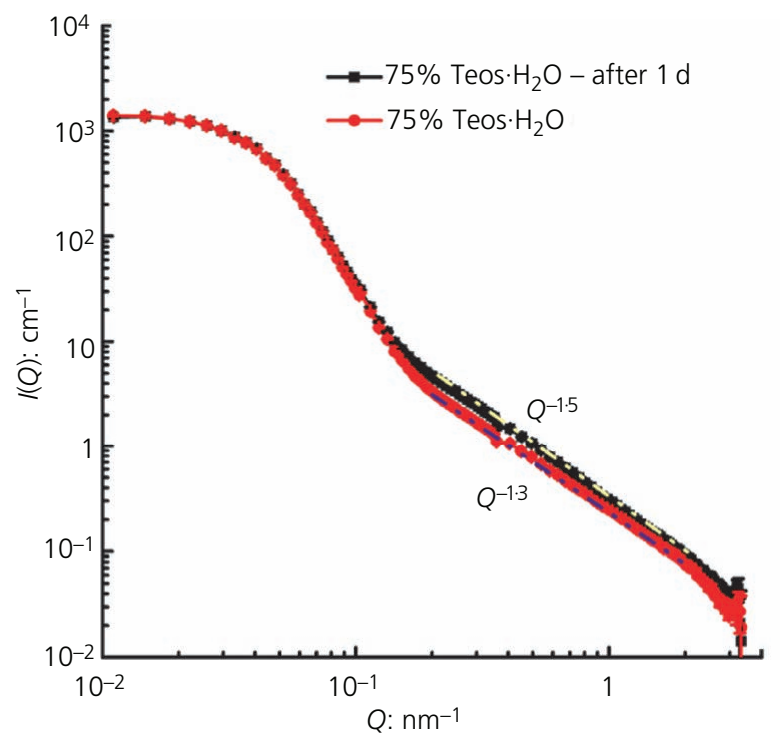

(a)

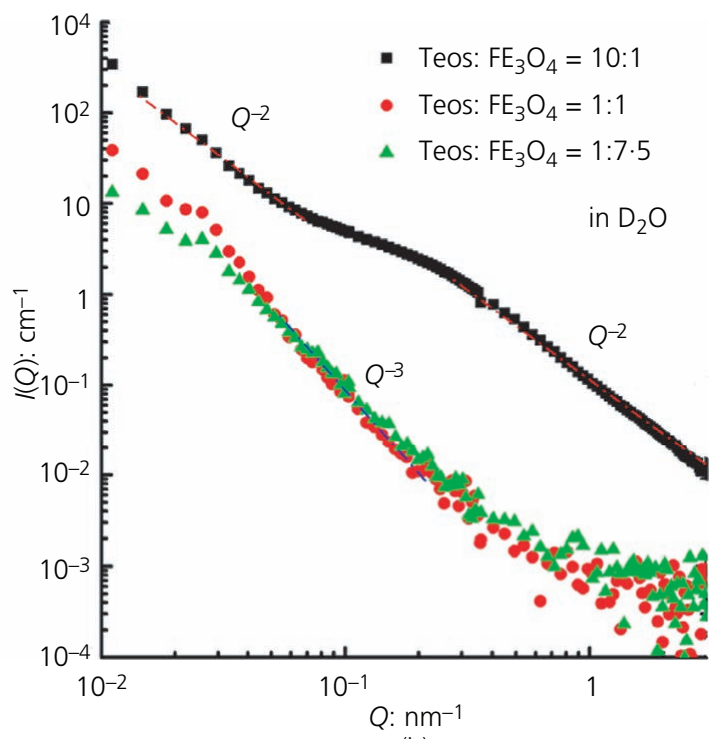

(b)

Figure 9. (a) Sans scattered intensity against scattering vector $\mathbf{Q}$ for gelatin hydrogels in the presence of prehydrolyzed Teos $\left(\mathrm{Teos} \cdot 4 \mathrm{H}_{2} \mathrm{O}\right)$ and measured again after $1 \mathrm{~d}$; (b) Sans scattered intensity against scattering vector $\boldsymbol{Q}$ for silica gel synthesis in the presence of magnetite nanoparticles in heavy water 
scattering curves show only small changes in the high- $Q$ range. These results imply that the growing silica network attaches only to the helical gelatin network (high- $Q$ structure). There is no significant change in the structure of the large dense spherical gelatin particles (low- $Q$ structure).

Figure 9(b) displays Sans scattering patterns of the silicification of ferrogels with different Teos-to-magnetite ratios in heavy water, matching the scattering of magnetite and visualizing the silica component. The scattering of the samples with lower Teos-tomagnetite ratios (1:1 and 1:7.5) shows lower scattering intensity in the $Q$ range than the sample with high a Teos/magnetite ratio. The samples with Teos-magnetite ratios of $1: 1$ and 1:7.5 show $Q^{-3}$ scattering in the intermediate- $Q$ range, indicating a rough surface layer of silica on the magnetite particles.

With a Teos-magnetite ratio around 10:1 the scattering curve shows a shoulder at the intermediate- $Q$ range, indicating colloid-like scattering with high polydispersity. Fitting a Beaucage expression to this intermediate- $Q$-range curve shows colloids with $R_{\mathrm{g}}$ more than $16 \mathrm{~nm}$ - that is, a spherical diameter of $41 \mathrm{~nm}\left(2 \cdot 58 R_{\mathrm{g}}\right)$. The power-law exponent of the low- $Q$-range curve is around 2 , indicating the appearance of some large aggregates at high Teos concentration. This indicates that during the silicification process, the magnetite particle surfaces are mineralized first.

To elucidate further the interplay of silica and magnetite mineralization assisted by collagen, the authors performed molecular simulation studies on the association of Teos and silanol to the triple-helical collagen fiber discussed beforehand $\left((\mathrm{Gly}-\mathrm{Hyp}-\mathrm{Pro})_{n}+\mathrm{Fe}_{x}(\mathrm{OH})_{y}\right)$. For this, an early-stage snapshot of iron hydroxide cluster association with collagen (involving four $\mathrm{Fe}^{\mathrm{II}}$ and eight $\mathrm{Fe}^{\mathrm{III}}$ complexes) was selected. The authors then derived a statistical analysis of suitable association sites for Teos and silanol molecules. For this purpose, parallel simulation runs each comprising 250 association attempts were employed, analogous to earlier studies. These involved docking of iron (II/ III) hydroxide to the collagen fiber ${ }^{15}$ as well as calcium and phosphate ion association. ${ }^{62}$ (See the online supplementary material for details on the molecular simulation models.) Such docking from a random incoming direction, followed by relaxation in aqueous solution, showed three categories of silanol/ Teos binding to the $\mathrm{Fe}_{x}(\mathrm{OH})_{y}$-collagen complex: I - silanol/Teos association with iron hydroxide clusters; II - silanol/Teos association with both iron hydroxide clusters and collagen; and III - association with collagen only. Figure 10 illustrates the molecular surface of collagen (green) and iron hydroxide clusters (black) along with a heat map representation of all observed silanol/Teos binding sites (gray/pale red). Despite the small number of iron hydroxide clusters, a large fraction of silanol/Teos association attempts lead to contacts with either iron hydroxide clusters along (I) or binding to both iron hydroxide clusters and collagen side chains (II). Taking the ratio of the molecular surface areas of iron hydroxide clusters and the collagen triple helix into account it is found that silanol and Teos molecules show a seven-

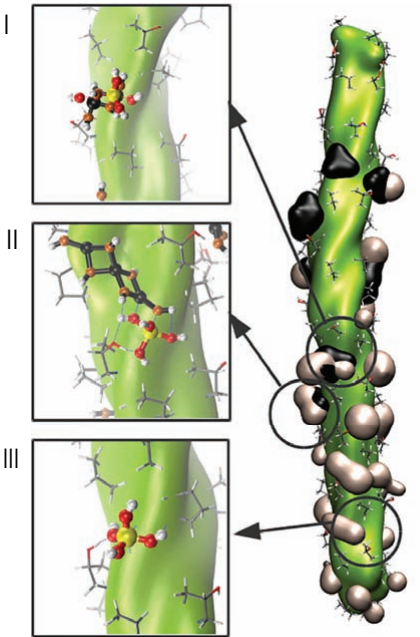

(a)



(b)
Figure 10. (a) Heat map of silanol association with collagen and iron hydroxide clusters. Three types of binding motifs are discriminated (left) as association with pure magnetite (I) or with the interface between collagen and magnetite (II) or with blank collagen (III). In I, silanol shows exchange of hydroxide ions with iron hydroxide, supposedly starting interlayer growth at this precursor stage. (b) Analogous analysis for Teos association

to eight-fold preference of arrangements I and II over association with blank collagen (III).

While the association of Teos leads to comparably weak hydrogen bonding and results in weak structural rearrangements, silanol exhibits a strong interplay with iron hydroxide, leading to ion reorganization in favor of additional salt bridges. The implication for the authors' experimental investigation of filling the collagen-magnetite ferrogel with silica is that Teos molecules should preferentially associate with magnetite nanoparticle surfaces and give rise to silica precipitation through heterogeneous nucleation. Rather than simply 'filling an empty space' within the ferrogel, this suggests the formation of a magnetite-silica interface, followed by silica growth. The authors argue that this mechanism accounts for the formation of a particularly robust collagen-magnetite-silica composite material.

This mechanistic concept of composite formation is illustrated in Figure 11. In the first step, the magnetite nanoparticles nucleate on the collagen fibers. Growth of silica then occurs through heterogeneous nucleation supported by magnetite, leading to coating of magnetite with silica. After the initial onset of silica-magnetite interface growth, further structured growth of silica occurs along the helices through both incorporation of silica building units that are directly bound to the helical structure and/or merging with other nucleation sites. This elongated structure growth ultimately leads to the formation of bulk silica embedded into the ferrogel.

The diffusion-based mineralization of gels almost inevitably leads to the formation of gradients (concentrations, $\mathrm{pH}$ etc.) during the 




Figure 11. Suggested mechanism of silica-ferrogel composite nucleation and growth. The interface layer between silica and magnetite grows first and bulk silica grows afterward. This leads to a hierarchically organized composite

synthesis, which also results in gradients of mineral content in the finished materials. Observation of cross-sections with an energydispersive X-ray spectroscopy (EDX) line scan shows how the magnetite content decreases toward the center of the materials. In silicified samples, the silica content can be observed to decline even faster than the magnetite content in an almost exponential fashion (Figure S2(a) in the online supplementary material).

Further influence on the silica content can be exerted by infiltrating iron (III) chloride before the silicification (see Table 3 and Figure 12). The trivalent iron ion can increase the silica condensation through an increase in ionic strength. It is known from literature to accelerate the gelation of silicon alkoxides. ${ }^{65}$ Infiltration of the ferrogel with a 10 or $100 \mathrm{mM}$ iron (III) chloride solution prior to silicification influences the deposition of silica and increases the silica content deeper in the material, away from the material surface. Looking at the superparamagnetic samples, with a $10 \mathrm{mM}$ iron (III) chloride solution, silica is almost evenly distributed throughout the material (see also Figure S2(b) in the online supplementary material).

A more even distribution of silica throughout the sample leads to a decreased concentration on the surface. For a $100 \mathrm{mM}$ solution, there is again a gradient toward the surface but the silica content in the material core is still increased. Assuming that both magnetite and free iron ions lead to an increase in silanol mineralization, one can assume that bringing in and evenly distributing additional iron ions might 'overpower' the influence of magnetite on the mineralization. This leads to an even silica distribution, while increasing the ionic strength too much by further increasing the iron ion concentration accelerates the silanol condensation to a point where the silica precursors simply can no longer infiltrate the material evenly before mineralization takes place.

The addition of silica to the materials has a clear influence on the mechanical properties, with a notable increase in both hardness and Young's modulus, as determined by nanoindentation. Reversing the previously observed trend, the samples prepared with freeze-cast chitinous scaffolds show a higher surface hardness than the samples based on natural nacre scaffolds after silicification. The hardness measured for the chitin samples increases from 0.59 to $1.92 \mathrm{GPa}$, while the hardness of the nacre material increases from 0.83 to $1.22 \mathrm{GPa}$. Young's modulus was shown to increase from $9 \cdot 8$ to $23.4 \mathrm{GPa}$ in the chitin material and from 14.7 to $20.4 \mathrm{GPa}$ in the nacre-based material (see also Table 2).

Comparing the samples within one group, the highest surface hardness is always observed for the samples prepared without addition of iron salts. The lowest hardness is observed for the samples prepared with $10 \mathrm{mM}$ iron (III) chloride, where silica is distributed more evenly throughout the sample with less silica on the surface. Surface hardness goes hand in hand with the silica concentration - that is, the increase in overall mineral concentration as determined by EDX. The correlation between silica concentration and Young's modulus is not as clear, but a definite increase in the value is observed for every silicified material (see Table 2 for details).

Table 3. EDX results (wt. \%) from polished surfaces of pressed composites without silicification and after silicification

\begin{tabular}{|c|c|c|c|c|c|c|}
\hline & \multicolumn{3}{|c|}{ EDX surface } & \multicolumn{3}{|c|}{ EDX core } \\
\hline & Magnetite & Silica & Total & Magnetite & Silica & Total \\
\hline \multicolumn{7}{|c|}{ Superparamagnetic material } \\
\hline \multicolumn{7}{|l|}{ Nacre-based } \\
\hline No silicon & $67 \cdot 5$ & & $67 \cdot 5$ & $25 \cdot 8$ & & $25 \cdot 8$ \\
\hline Milli-Q & $58 \cdot 4$ & $12 \cdot 9$ & $71 \cdot 2$ & $37 \cdot 3$ & $3 \cdot 4$ & $40 \cdot 7$ \\
\hline $10 \mathrm{mM}$ iron (III) chloride & $60 \cdot 0$ & $9 \cdot 2$ & $69 \cdot 2$ & $29 \cdot 0$ & $7 \cdot 3$ & $36 \cdot 3$ \\
\hline $100 \mathrm{mM}$ iron (III) chloride & $63 \cdot 0$ & $13 \cdot 7$ & $76 \cdot 7$ & 38.0 & 8.0 & $46 \cdot 0$ \\
\hline \multicolumn{7}{|l|}{ Chitin-based } \\
\hline No silicon & $64 \cdot 2$ & & $64 \cdot 2$ & $10 \cdot 2$ & & $10 \cdot 2$ \\
\hline Milli-Q & $47 \cdot 4$ & $32 \cdot 8$ & $80 \cdot 2$ & 14.9 & $5 \cdot 1$ & $20 \cdot 1$ \\
\hline $10 \mathrm{mM}$ iron (III) chloride & $63 \cdot 8$ & $12 \cdot 4$ & $76 \cdot 2$ & $19 \cdot 9$ & $20 \cdot 0$ & $39 \cdot 9$ \\
\hline 100 mM iron (III) chloride & $55 \cdot 8$ & $19 \cdot 8$ & $75 \cdot 6$ & $16 \cdot 7$ & $6 \cdot 3$ & $23 \cdot 0$ \\
\hline \multicolumn{7}{|c|}{ Ferrimagnetic materials } \\
\hline \multicolumn{7}{|l|}{ Nacre-based } \\
\hline No silicon & $60 \cdot 9$ & & $60 \cdot 9$ & 8.7 & & $8 \cdot 7$ \\
\hline $10 \mathrm{mM}$ iron (III) chloride & $45 \cdot 4$ & 23.9 & $69 \cdot 3$ & $19 \cdot 4$ & $15 \cdot 7$ & $35 \cdot 1$ \\
\hline $100 \mathrm{mM}$ iron (III) chloride & $59 \cdot 5$ & $10 \cdot 3$ & $69 \cdot 9$ & $15 \cdot 7$ & $9 \cdot 4$ & $25 \cdot 1$ \\
\hline
\end{tabular}



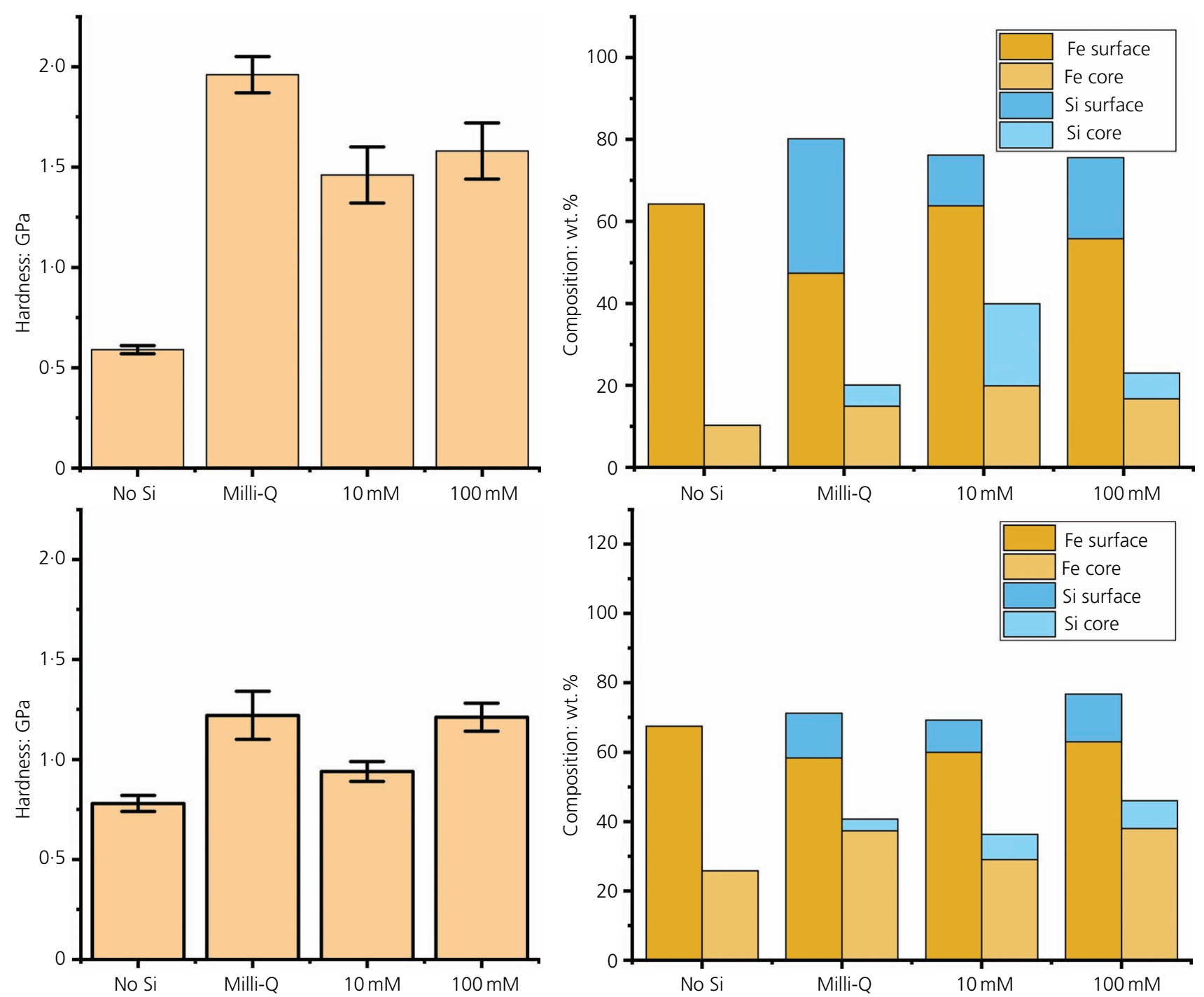

Figure 12. Diagrams showing hardness and mineral composition for the chitin-based (top row) and nacre-based (bottom row) superparamagnetic composites before and after silicification for different concentrations of iron (III) chloride

Also of interest are the mechanical properties of the core of the material, containing a lot less magnetite than observed on the surface. The hardness of cross-sections of the samples was analyzed with Vickers hardness (HV) testing. This test uses indentations orders of magnitude larger than nanoindentation, thus measuring the microhardness of the cross-sections. This way, hardness values are less influenced by the exact location of the indent because they are larger than the present structural features - that is, individual organic and inorganic layers. It is again evident how silica is suitable for increasing the hardness. HV measurements show how the material's core is rather soft with an $\mathrm{HV}$ of $30-40$, which is below, for example, the HV of human dentin. Still, the hardness could be increased by a factor of $25-30 \%$ with silicification from 32 to $41 \mathrm{HV}$. The hardness could again be observed to increase with increasing silica content when going from 0 to $100 \mathrm{mM}$ iron (III) chloride preimpregnation (Figure 13).

Silicification was also carried out for the ferrimagnetic nacrebased materials. An increase in hardness from 0.78 to $1.31 \mathrm{GPa}$ and an increase in Young's modulus from 14.6 to $18 \cdot 5 \mathrm{GPa}$ were observed. The dependence of the silica distribution on iron chloride preloading is observed to be different in these materials. The material infiltrated with $10 \mathrm{mM}$ iron (III) chloride shows the highest degree of silicification in the outer and core region and thus also the highest hardness and stiffness. This might be due to the different residual salts such as potassium hydroxide $(\mathrm{KOH}) /$ potassium nitrate resulting from the different magnetite synthesis paths. Again, the hardness increased with increasing degree of silicification, while Young's modulus increased with 


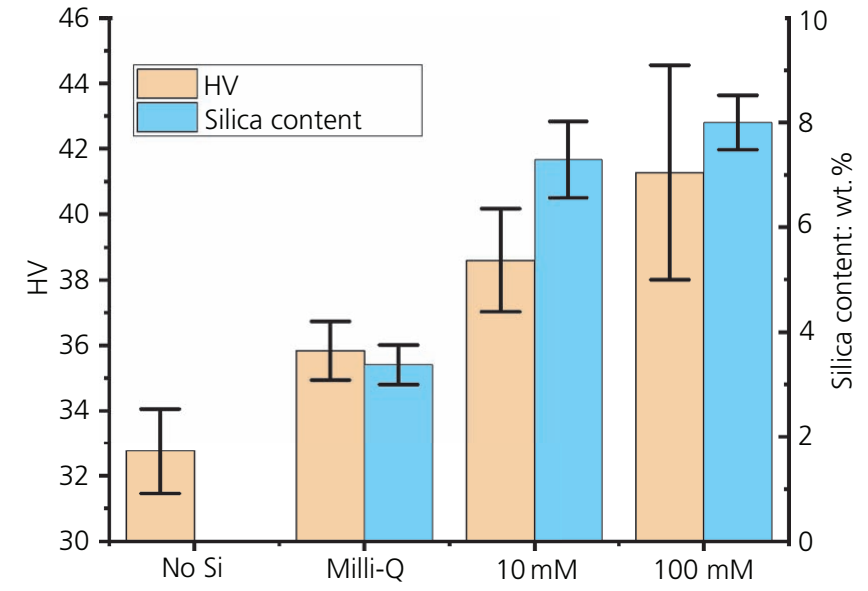

Figure 13. HV (beige) compared to silica content (blue) in different chitin-based magnetite composites mineralized after preimpregnation with different iron chloride concentrations (note that for better visualization the $y$-scale for HV does not start at 0 )

silicification, but no clear correlation to silica concentrations was obvious.

\section{Conclusion}

Bioinspired hybrid composite materials were designed, picking up a range of functional elements inspired by different biominerals as model systems. The authors showed iterative improvement in the mechanical properties by incorporation of each of these elements. By mimicking the structure of nacre, a hydrogel-filled scaffold was synthesized which could subsequently be mineralized with magnetite. The mineralized gelatin ferrogel mimics the organic-inorganic composite from the hard cusps of chiton teeth. The alignment of magnetite into linear superstructures seen in chiton teeth was reproduced by making use of a magnetic field and led to an increase in hardness and stiffness of the material. At the same time, it added anisotropic magnetic and mechanical properties to the ferrogel. The limited degree of mineralization of the bioinspired composites compared to the very high degrees of mineralization seen in hard and tough biominerals can be seen as a limiting step for further improvement of the material. Thus, the concept of a filler mineral was adapted from the model biomineral found in the teeth of limpets. Silicification was used not only to increase the overall degree of mineralization, but also to influence the mineral distribution within the composite.

The very first steps of silica mineralization were investigated using molecular simulation, showing how both gelatin and magnetite particles can interact with dissolved silica precursors. The results suggested that, in particular, the interface between magnetite and gelatin is interacting with silanol species in a way to catalyze the mineralization.

The mineralization of gelatin hydrogels with both magnetite and silica as well as the structural changes of the hydrogels and ferrogels during the silicification was investigated with Sans, indicating the overgrowth of magnetite particles with silica. The formation of individual silica particles was observed only at high Teos concentrations.

As is seen in Figure 14, both the incorporation of a layered matrix into the material and the silicification step led to substantial increases in hardness and stiffness. The silicified composites have a structure similar to mollusk teeth with iron-rich highly mineralized hard outer shells and a softer core being mineralized to a higher degree with a softer filler mineral. Further influence could be exerted through preimpregnation with iron salts prior to silicification. This gave control over the silica distribution within the composites with direct consequences on the mechanical properties of the core and shell of the material. Generally, an increase in silica content also improved both hardness and stiffness. In the future, these materials need to be tested on their actual 'macroscopic' performance regarding fracture and abrasion resistance. In particular, the change in performance depending on the inner structure and mineral distribution of the material should be of high interest.

The hardness and stiffness values of these composites lie on the same order of magnitude as those of many natural biominerals although they do not reach the peak performance of some of the model materials. This is also in part due to the mineralization processes mimicking natural processes. These are very slow in nature and controlled microscopically on a level of detail which far surpasses what is possible in simplified laboratory protocols. Still, this work shows how inspiration from biological minerals can be seen as one big toolbox. The combination of the ideas and functional elements from multiple different model biominerals can

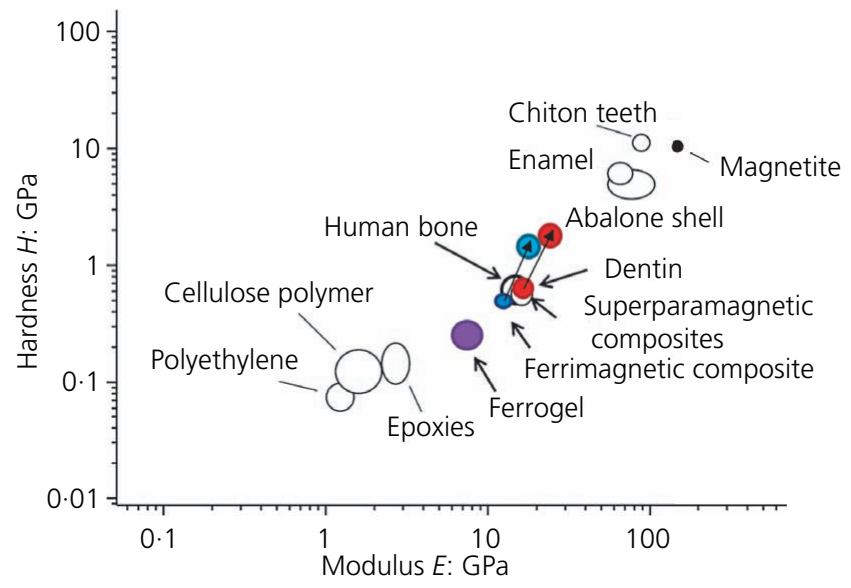

Figure 14. Ashby plot showing the hardness and stiffness of various organic polymers ${ }^{66}$ and biominerals, ${ }^{22,50}$ in comparison to the synthesized materials (purple: ferrogels; blue: ferrimagnetic composites; red: superparamagnetic composites). A clear improvement is visible when incorporating the layered nacre scaffold into the ferrogel. The arrows show the further increase in mechanical properties after silicification of each composite 
be combined to tailor a synthetic material step by step toward the desired properties.

\section{Acknowledgements}

The authors gratefully acknowledge the funding of this project by Deutsche Forschungsgemeinschaft within SPP1569 Molecular Bionics. The authors also thank the computing resources and support provided by the Erlangen Regional Computing Center. Maria Siglreitmeier thanks the University of Konstanz for supporting a research stay at the University of California Riverside. David Kisailus and Steven Herrera gratefully acknowledge support from the Multi-university Research Initiative (AFOSR-FA9550-15-1-0009) and Army Research Office (W911NF-15-1-0306). The authors thank Stefan Kilpert from the group of Prof. Dr Joachim Bill at the University of Stuttgart for performing the nanoindentation measurements on the pressed composite materials.

\section{Appendix 1: Experimental}

\section{A1.1 Chemicals}

The following commercially available chemicals were used without further purification: iron (II) chloride tetrahydrate $\left(\mathrm{FeCl}_{2} \cdot 4 \mathrm{H}_{2} \mathrm{O}\right)$ (Sigma-Aldrich), iron (III) chloride hexahydrate $\left(\mathrm{FeCl}_{3} \cdot 6 \mathrm{H}_{2} \mathrm{O}\right)$ (Sigma-Aldrich), iron (II) sulfate heptahydrate $\left(\mathrm{FeSO}_{4} \cdot 7 \mathrm{H}_{2} \mathrm{O}\right)$ (Sigma-Aldrich), potassium nitrate (SigmaAldrich), potassium hydroxide (Sigma-Aldrich), gelatin type B (225 Bloom, Sigma-Aldrich), 0·1 M sodium hydroxide $(\mathrm{NaOH})$ solution (Merck), 0.1 M hydrochloric acid ( $\mathrm{HCl}$ ) solution (Merck), 4-chloro- $m$-cresol (Fluka), EtOH (VWR), methanol (VWR), acetic acid (Roth), tetraethyl orthosilicate (Sigma-Aldrich), chitosan (Polysciences Inc.) and acetic anhydride (Acros Organics).

\section{A1.2 Demineralization of nacre matrix}

Sandblasted shells of $H$. laevigata were cut into pieces with an area of around $2 \mathrm{~cm} \times 1 \mathrm{~cm}$. The nacre pieces were demineralized using $10 \%$ acetic acid, replacing the solvent every day for at least $5 \mathrm{~d}$. The demineralized organic matrix was then washed with Milli-Q until a neutral $\mathrm{pH}$ was reached.

\section{A 1.3 Chitosan freeze-casting}

A 3 wt. $\%$ chitosan solution (in $6 \%$ acetic acid) was poured into a Teflon cylinder with a copper-bottom plate. The Teflon tube was isolated with plastic foam, and the bottom plate was cooled with liquid nitrogen. The solution started to freeze unidirectionally from the bottom to the top. During this freezing, a lamellar structure was created according to the unidirectional freezing effect. ${ }^{60}$ After complete solidification, the cylindrical ice block was pushed out of the Teflon cylinder. A water-free chitosan scaffold containing some acetic acid residuals was obtained after $2 \mathrm{~d}$ of lyophilization (for $20 \mathrm{ml}$ chitosan solution). For further use, the chitosan scaffold was acetylated to chitin following the method of $\mathrm{Xu}$ et al. ${ }^{67}$ Scaffold pieces were submerged in $1 \mathrm{M}$ methanolic acetic anhydride solution for $24 \mathrm{~h}$ and then washed with $20 \%$ acetic acid for $24 \mathrm{~h}$ and afterward washed with $0.5 \mathrm{M}$ sodium hydroxide solution and neutralized with Milli-Q. After neutralization, the chitin scaffold was frozen and freeze-dried again.

\section{A1.4 Gelatin infiltration}

Gelatin gels were prepared by mixing different amounts of gelatin granules with Milli-Q water and were allowed to swell for $24 \mathrm{~h}$. The mixture was then homogenized by stirring at $50^{\circ} \mathrm{C}$ for $2 \mathrm{~h}$. In order to avoid bacterial growth, a $5 \mathrm{wt} . \%$ solution of 4-chloro- $m$ cresol in methanol was added $(0.15 \mathrm{ml}$ per $1 \mathrm{~g}$ of gelatin granules). Then, the gelatin was allowed to settle into a gel at room temperature until further usage.

The cut scaffold pieces (either demineralized nacre or freeze-cast chitin) were placed in a crystallization dish filled with $20 \mathrm{ml}$ molten gelatin at $55^{\circ} \mathrm{C}$. A filter paper was placed above the scaffold pieces to keep them evenly immersed. The crystallization dish was placed in a vacuum desiccator, and water-jet vacuum was applied until the solution started to boil. The vacuum was then removed, forcing the molten gelatin into the scaffold pores. This was repeated three times. The gelatin was then allowed to settle into a gel, and the gelatin-filled scaffolds were carefully cut from the gel.

\section{A1.5 Superparamagnetic layered composites}

All solutions used for magnetite mineralization were degassed with nitrogen prior to usage.

The gelatin-filled scaffolds were introduced into a solution of $0 \cdot 2 \mathrm{M}$ iron (III) chloride and $0 \cdot 1 \mathrm{M}$ iron (II) chloride. The solution was then stored at $4{ }^{\circ} \mathrm{C}$ for $96 \mathrm{~h}$. The gels loaded with iron chlorides were washed with water and placed in a $0 \cdot 1 \mathrm{M}$ sodium hydroxide solution for $150 \mathrm{~min}$. These reaction cycles were repeated up to six times. The samples were then washed extensively with Milli-Q water and air-dried for further usage.

\section{A1.6 Ferrimagnetic layered composites}

All solutions used for magnetite mineralization were degassed with nitrogen prior to usage.

The gelatin-filled scaffolds were introduced into a $0 \cdot 3 \mathrm{M}$ iron (II) sulfate solution also containing $0 \cdot 01 \mathrm{M}$ sulfuric acid $\left(\mathrm{H}_{2} \mathrm{SO}_{4}\right)$. The solution was then stored at $4{ }^{\circ} \mathrm{C}$ for $96 \mathrm{~h}$. The scaffold loaded with iron sulfate was washed with water and placed in a solution of $0 \cdot 1 \mathrm{M}$ potassium hydroxide and $0 \cdot 3 \mathrm{M}$ potassium nitrate for $20 \mathrm{~h}$. The reaction cycles were repeated up to six times. The samples were then washed with Milli-Q water at $4^{\circ} \mathrm{C}$ for at least $24 \mathrm{~h}$ and air-dried for further usage.

\section{A1.7 Teos infiltration into nacre scaffold}

A demineralized nacre scaffold was placed in an excess of EtOH to remove the water from the pores. Tetraethyl orthosilicate $(28 \mathrm{~g})$ was prehydrolyzed with $10 \cdot 4 \mathrm{ml} 0 \cdot 01 \mathrm{M}$ hydrochloric acid under vigorous stirring. The initial two phases became miscible after approximately $1 \mathrm{~h}$, and stirring was continued for another hour. Then the nacre scaffold was placed in the Teos solution, and the 
solution was left to dry in air. The scaffold could then be broken/ cut from the excess silica that had formed around it.

\section{A1.8 Silicification of gelatin and ferrogel composites}

Samples were reswollen in Milli-Q water or solutions of 10 or $100 \mathrm{mM}$ iron (III) chloride for $24 \mathrm{~h}$. After $24 \mathrm{~h}$, all samples were washed with Milli-Q water and placed in a $75 \% \mathrm{EtOH}$ solution on a shaking board for $3 \mathrm{~d}$. Tetraethyl orthosilicate $(28 \mathrm{~g})$ was prehydrolyzed with $10.4 \mathrm{ml} \quad 0.01 \mathrm{M}$ hydrochloric acid under vigorous stirring. The initial two phases became miscible after approximately $1 \mathrm{~h}$, and stirring was continued for another hour. The sample was then introduced into a solution of $67 \cdot 5 \% \mathrm{EtOH}$, $7 \cdot 5 \%$ prehydrolyzed Teos and $25 \%$ Milli-Q water. The solution was again placed on a shaking board for $3 \mathrm{~d}$. The sample was then washed and placed in a solution of $75 \% \mathrm{EtOH}$ on a shaking board for $3 \mathrm{~d}$ to remove excess reagents. After washing and storing in Milli-Q water at $4^{\circ} \mathrm{C}$ for $24 \mathrm{~h}$, the sample could be frozen with liquid nitrogen and the solvent was removed by lyophilization. The lyophilized sample was carefully cut into shape to fit into the die of a hydraulic press. In the last step, the sample was pressed with a pressure of $300 \mathrm{MPa}$ overnight to obtain a compact material.

\section{Appendix 2: Analytical methods}

\section{A2.1 X-ray diffraction}

XRD diffractograms were recorded on a Bruker D8 Discover diffractometer using a Lynxeye XE detector to suppress the iron fluorescence background.

\section{A2.2 Infrared spectroscopy}

Attenuated total reflectance - Fourier transform infrared spectra were recorded with a PerkinElmer Spectrum 100 spectrometer.

\section{A2.3 Scanning electron microscopy}

SEM images were recorded either with a Zeiss 1540 XB crossbeam microscope using the Inlens detector at an acceleration voltage of $2 \mathrm{kV}$ or with a Hitachi TM300 microscope using a backscattered-electron detector at $15 \mathrm{kV}$ acceleration voltage.

\section{A2.4 Polishing for EDX and nanoindentation}

Samples were polished by hand using a tripod sample holder. Polishing paper with grain sizes of $6 \mu \mathrm{m}, 3 \mu \mathrm{m}, 1 \mu \mathrm{m}$ and $300 \mathrm{~nm}$ were used consecutively.

\section{A2.5 Energy-dispersive X-ray spectroscopy}

Elemental distribution on polished surfaces was determined by EDX using a Hitachi TM300 microscope in analysis mode and a Bruker Quantax 70 detector. A cleaned silicon wafer was used as the standard. Mineral contents were calculated under the assumption that all iron is present in the form of magnetite and all silicon is present in the form of silica.

\section{A2.6 Transmission electron microscopy}

For TEM examination, the formed composite material was dehydrated with a graded EtOH series and embedded in LR White resin (medium grade). The sample was cut perpendicular with a diamond knife in a Leica ultracut UCT ultramicrotome and transferred onto a Formvar-coated copper grid. TEM and electron diffraction were performed on a Zeiss Libra 120 microscope operating at $120 \mathrm{kV}$.

\section{A2.7 Nanoindentation}

The measurements on ferrogels and unpressed magnetite composites were performed by Steven Herrera in the group of Dr David Kisailus at the University of California Riverside. Nanoindentation studies were performed in ambient air using a triboindenter nanomechanical testing system (TI-950 nanoindenter, Hysitron, USA) equipped with both a low-load (maximum $13 \mathrm{mN}$ ) and a high-load (maximum $15 \mathrm{~N}$ ) transducer equipped with a cube corner tip. The embedded and polished samples were measured displacement controlled $(1000 \mathrm{~nm})$ with a loading-unloading profile. The curves were analyzed according to the Oliver-Pharr method, and the average value for Young's modulus and hardness resulting from the loading-unloading curves are reported.

The mechanical performance of the pressed and silicified samples was tested by Stefan Kilper in the group of Joachim Bill at the University of Stuttgart (Nanoindenter XP, Keysight) with a pyramidal cube corner diamond tip. The nanoindentation was performed in displacement-controlled continuous stiffness measurement mode up to a displacement of $2 \mu \mathrm{m}$.

For evaluation, 75 indentation experiments on every sample were performed and curves in accordance with the theory ${ }^{68,69}$ have been chosen for calculation of the mean values of Young's modulus and hardness.

\section{A2.8 Vickers hardness}

The HV of material cross-sections was determined using a Leitz Miniload 2 tester with a load of $300 \mathrm{~g}$.

\section{A2.9 Superconducting quantum interference device}

The Squid measurements were performed by Aleksej Laptev in the group of Apl. Prof. Dr Mikhail Fonin at the University of Konstanz. Magnetization measurements were carried out by using a quantum design Squid $5 \mathrm{~T}$ magnetic property measurement system. For measurements, dried ferrogels were introduced into gelatin capsules and magnetization loop measurements at 2 and $298 \mathrm{~K}$ were performed.

\section{A2.10 Thermogravimetric analysis}

The mineral content of the hydrogels was determined by means of TGA (Netzsch, Selb, Germany). Measurements were carried out at a heating rate of $5 \mathrm{~K} / \mathrm{min}$ under a constant oxygen flow. Samples were scanned from 293 to $1273 \mathrm{~K}$.

\section{A2.11 Sans experiments}

Sans and very small-angle neutron scattering (Vsans) experiments were carried out at the KWS- $1,{ }^{70}$ KWS-2 and KWS- $3^{71}$ diffractometers of the Jülich Centre for Neutron Science (JCNS) 
outstation at the Heinz Maier-Leibnitz Zentrum in Garching, Germany. Four configurations were used at KWS-1 and KWS-2, namely, sample-to-detector distances of 2, 8 and $20 \mathrm{~m}$; collimation lengths of 8 and $20 \mathrm{~m}$; and wavelength of $7 \AA(\Delta \lambda \lambda=10 \%$ of KWS- 1 and $20 \%$ of KWS-2). These settings allowed covering a $Q$ range from 0.01 to $3 \mathrm{~nm}^{-1}$. A two-dimensional positionsensitive detector was used to detect neutrons scattered from the samples. In order to cover the broader length scale of the network structure, Vsans experiments were carried out at the KWS-3 diffractometer using the parabolic mirror as an optical element and covering the smaller $Q$ range from 0.0001 to $0.002 \AA^{-1} .^{71}$ Samples were measured in a sample cell between two quartz windows with a path length of $1 \mathrm{~mm}$. Plexiglas was used as a secondary standard to calibrate the scattering intensity in absolute units at KWS- 1 and KWS-2. ${ }^{70}$ Data correction and calibration were performed using the software QtiKWS. ${ }^{72}$ Fitting of the Sans-Vsans data was done using software modules provided by JCNS: QtiKWS and National Institute of Standards and Technology Igor $^{73}$ analysis packages.

\section{A2.12 Molecular simulation}

\section{A2.12.1 Teos model and QM calculation of O-Si-O-C torsion potential}

The MM model of Teos was adopted from the second-generation general Amber force field (Gaff2), ${ }^{74}$ refined by quantum calculations to improve the Coulomb interaction and the $\mathrm{O}-\mathrm{Si}-\mathrm{O}-\mathrm{C}$ torsion potentials. The quantum (density functional theory (DFT)) calculations were performed with Gaussian using the B3LYP/6-31G* as DFT functional and basis set, respectively. After geometry relaxation, partial charges were assigned from restrained electrostatic potential fits. ${ }^{75}$

To ensure realistic Teos structures, the authors found that refitting the torsion potential for the $\mathrm{O}-\mathrm{Si}-\mathrm{O}-\mathrm{C}$ angle is needed. DFT calculations of a single Teos molecule in the gas phase were employed for a relaxed potential energy scan of the torsion, and a refined potential as denoted in Table 4 was obtained.

\section{A2.12.2 Intermolecular force calculations}

For the intermolecular force calculations, the authors used Coulomb + Lennard-Jones models for most of the interactions as listed in Table 5. For the ion-ion interactions in both iron oxide/ hydroxide and silanol, however, specific Buckingham-type potentials were used as described in Table 6 .

Table 4. Improved potential (in $\mathrm{kJ} / \mathrm{mol}$ ) for the O-Si-O-C torsion in the Teos molecules as described by cosine functions $U(\phi)=A[1+\cos (m \phi-\delta)]$, with $m=1-4$

\begin{tabular}{crrr|} 
Torsion & $\boldsymbol{A}: \mathbf{k J} / \mathbf{m o l}$ & \multicolumn{1}{c}{$\boldsymbol{\delta}:^{\circ}$} & $\boldsymbol{m}$ \\
\hline O-Si-O-C & 21.0890 & 0.00 & 1.0 \\
O-Si-O-C & 18.2163 & 180.00 & 2.0 \\
O-Si-O-C & 0.1101 & 0.00 & 3.0 \\
O-Si-O-C & 0.2103 & 0.00 & 4.0
\end{tabular}

Table 5. Lennard-Jones parameters used to describe the van der Waals interactions with the exception of ion-ion potentials listed in Table 6

\begin{tabular}{|c|c|c|}
\hline Name & $\varepsilon: \mathrm{kJ} / \mathrm{mol}$ & $\sigma: \AA$ \\
\hline $\mathrm{Fe} 2^{8}$ & 0.113420 & $2 \cdot 59607886$ \\
\hline $\mathrm{Fe} 3^{8}$ & 0.0567809 & $2 \cdot 4695712$ \\
\hline O2/O3 & 0.73567 & $2 \cdot 82693$ \\
\hline $\mathrm{H} 2 / \mathrm{H} 3$ & 0.00000 & $1 \cdot 29370$ \\
\hline Ox & 0.87864 & 2.9599219 \\
\hline $\mathrm{Si}^{10}$ & $1 \cdot 255$ & 1.795939 \\
\hline OSi ${ }^{10}$ & 0.6276 & $1 \cdot 8520624$ \\
\hline $\mathrm{HSi}^{10}$ & 0.087864 & 1.224620 \\
\hline $\mathrm{SI}^{11-13}$ & $1 \cdot 29704$ & $3 \cdot 80414$ \\
\hline$C 3^{11-13}$ & 0.45104 & $3 \cdot 39771$ \\
\hline $\mathrm{SIH} 1^{11-13}$ & 0.08703 & $2 \cdot 42200$ \\
\hline $\mathrm{SIHC}^{11-13}$ & 0.08703 & $2 \cdot 60018$ \\
\hline $\mathrm{OS}^{11-13}$ & 0.30376 & $3 \cdot 15610$ \\
\hline NT & 0.71128 & $3 \cdot 25001$ \\
\hline CT & 0.45773 & $3 \cdot 39968$ \\
\hline $\mathrm{H} 1$ & 0.06569 & $2 \cdot 47136$ \\
\hline C & 0.35982 & $3 \cdot 39968$ \\
\hline 0 & 0.87864 & 2.95993 \\
\hline $\mathrm{N}$ & 0.71128 & $3 \cdot 25001$ \\
\hline $\mathrm{HC}$ & 0.06569 & $2 \cdot 64954$ \\
\hline $\mathrm{OH}$ & 0.88031 & 3.06648 \\
\hline $\mathrm{HO}$ & 0.00000 & 0.00000 \\
\hline $\mathrm{H}$ & 0.06569 & 1.06908 \\
\hline OW & 0.63626 & $3 \cdot 15071$ \\
\hline $\mathrm{HW}$ & 0.00000 & 0.89803 \\
\hline
\end{tabular}

The Lorentz-Berthelot mixing rules ${ }^{76,77}$ are applied. Parameters that are not highlighted by links to specific references are taken from Gaff for organic molecules ${ }^{78,79}$

Table 6. Specific ion-ion interactions described by the Buckingham potential

\begin{tabular}{|c|c|c|c|}
\hline Name & $A: \mathrm{kJ} / \mathrm{mol}$ & $B: \AA$ & C: $\mathrm{kJ} /\left(\mathrm{mol} \AA^{6}\right)$ \\
\hline Si-Si ${ }^{11-13}$ & 7709907630000 & 0.0046 & $2429 \cdot 600577$ \\
\hline $\mathrm{OHSi}-\mathrm{OHSi}{ }^{11-13}$ & 623324.589 & 0.276 & $8207 \cdot 166803$ \\
\hline $\mathrm{Si}-\mathrm{OHSi}{ }^{11-13}$ & $4841569 \cdot 81$ & $0 \cdot 161$ & $4465 \cdot 432455$ \\
\hline $\mathrm{Fe} 2-\mathrm{Ox}{ }^{16}$ & $66970 \cdot 5$ & 0.3399 & 0.000 \\
\hline $\mathrm{Fe} 3-\mathrm{Ox}{ }^{16}$ & $95472 \cdot 2$ & 0.32990 & 0.000 \\
\hline $0-0 x^{14}$ & $2196420 \cdot 5$ & $0 \cdot 14900$ & $1968 \cdot 30$ \\
\hline
\end{tabular}

\section{A2.12.3 Molecular dynamics simulations}

The docking (zero-kelvin energy minimization) and the molecular dynamics simulations were carried out using DL_Poly with a time step of $1 \mathrm{fs}$ and damped shifted-force potentials with a cutoff of $16 \AA$. In full analogy to the authors' recent investigation of iron hydroxide cluster association with collagen, ${ }^{76}$ the Kawska-Zahn docking procedure was used to scan association sites and explore precipitate relaxation in solution.

Along this line, diffusion of ion clusters to collagen is mimicked by placing the solute at a $25 \AA$ distance from the precipitate + collagen complex. While the latter is initially kept frozen, solute docking is explored in the absence of solvent by energy minimization. The approximate association complexes are then immersed in aqueous solution (periodic simulation cell 
Table 7. Subsystems of the QM/MM calculations and energy changes upon proton transfer

\begin{tabular}{|c|c|c|c|}
\hline Proton transfer reaction & $\Delta E_{\mathrm{QM}}: \mathrm{eV}$ & $\Delta E_{\mathrm{MM}}: \mathrm{eV}$ & $\Delta E_{\mathrm{QM}}-\Delta E_{\mathrm{MM}}$ \\
\hline $\mathrm{Fe}^{\mathrm{III}}(\mathrm{OH})_{3}+\mathrm{OH}^{-} \rightarrow \mathrm{Fe}^{\prime \prime \prime} \mathrm{O}(\mathrm{OH})_{2}^{-}+\mathrm{H}_{2} \mathrm{O}$ & $-1 \cdot 5397$ & $-5 \cdot 2142$ & 3.6745 \\
\hline $\mathrm{Fe}^{\mathrm{II}}(\mathrm{OH})_{2}+\mathrm{OH}^{-} \rightarrow \mathrm{Fe}^{\mathrm{I}} \mathrm{OOH}^{-}+\mathrm{H}_{2} \mathrm{O}$ & $-1 \cdot 7420$ & $-7 \cdot 3701$ & $5 \cdot 6281$ \\
\hline $\mathrm{Fe}_{3}{ }^{\mathrm{III}}(\mathrm{OH})_{8}{ }^{+}+\mathrm{OH}^{-} \rightarrow \mathrm{Fe}_{3}{ }^{\prime \prime \prime} \mathrm{O}(\mathrm{OH})_{7}+\mathrm{H}_{2} \mathrm{O}$ & $-7 \cdot 5038$ & -14.594 & $7 \cdot 0901$ \\
\hline $\mathrm{Fe}_{2}{ }^{\text {III }} \mathrm{Fe}^{\prime \prime}(\mathrm{OH})_{8}+\mathrm{OH}^{-} \rightarrow \mathrm{Fe}_{2}{ }^{\prime \prime \prime} \mathrm{Fe}{ }^{\prime \prime} \mathrm{O}(\mathrm{OH})_{7}^{-}+\mathrm{H}_{2} \mathrm{O}$ & $-4 \cdot 2472$ & $-10 \cdot 314$ & $6 \cdot 0669$ \\
\hline $\mathrm{Fe}_{2}{ }^{\mathrm{III}} \mathrm{Fe}(\mathrm{OH})_{7}^{+}+\mathrm{OH}^{-} \rightarrow \mathrm{Fe}_{2}{ }^{\prime \prime \prime} \mathrm{FeO}(\mathrm{OH})_{6}+\mathrm{H}_{2} \mathrm{O}$ & $-9 \cdot 9054$ & $-11 \cdot 858$ & 1.9523 \\
\hline $\mathrm{Fe}^{\mathrm{III}} \mathrm{Fe}_{2}{ }^{\prime \prime}(\mathrm{OH})_{7}+\mathrm{OH}^{-} \rightarrow \mathrm{Fe}^{\mathrm{III}} \mathrm{Fe}_{2}{ }_{2} \mathrm{O}(\mathrm{OH})_{6}+\mathrm{H}_{2} \mathrm{O}$ & $-2 \cdot 8032$ & $-9 \cdot 1319$ & $6 \cdot 3287$ \\
\hline $\mathrm{Fe}_{3}{ }^{ }(\mathrm{OH})_{6}+\mathrm{OH}^{-} \rightarrow \mathrm{Fe}_{3} \mathrm{IO}(\mathrm{OH})_{5}^{-}+\mathrm{H}_{2} \mathrm{O}$ & $-1 \cdot 1958$ & $-7 \cdot 5804$ & $8 \cdot 7762$ \\
\hline $\mathrm{Fe}_{3}{ }^{\text {III }}(\mathrm{OH})_{9}+\mathrm{OH}^{-} \rightarrow \mathrm{Fe}_{3}{ }^{\prime \prime \prime} \mathrm{O}(\mathrm{OH})_{8}^{-}+\mathrm{H}_{2} \mathrm{O}$ & $-2 \cdot 9590$ & -8.0857 & $5 \cdot 0667$ \\
\hline
\end{tabular}

comprising more than 15000 water molecules) and subjected to relaxation. Within $100 \mathrm{ps}$, water is first allowed to relax according to frozen precipitate-collagen complexes and then fully flexible relaxation is explored from $400 \mathrm{ps}$ molecular dynamics runs at room temperature and ambient pressure.

\section{A2.12.4 QM/MM modeling of proton transfer between hydroxide ions}

To identify possible constellations for a proton transfer and to allow the further ripening from iron hydroxide to an iron oxide structure (magnetite), a combined QM/MM approach is used. The energy change related to the proton transfer is estimated from the energy difference as obtained from the MM models of reactant and product state plus the difference of proton affinity as obtained from quantum calculations (at the UMP2/AUG-cc-pVDZ level). Within a subtractive QM/MM approach, the authors use

$$
\text { 1. } \begin{aligned}
\Delta E^{\mathrm{PT}}= & \Delta E_{\mathrm{MM}}(\text { all })-\Delta E_{\mathrm{MM}}(\text { subsystem }) \\
& +\Delta E_{\mathrm{QM}}(\text { subsystem })
\end{aligned}
$$

where the subsystem is taken as the close neighborhood of the reacting hydroxide ions. To account for charge transfer between the iron ions and the oxygen atoms, a small set of subsystems was explored as listed in Table 7.

On average, the difference in proton affinity as given by $\Delta E_{\mathrm{QM}}$ (subsystem) $-\Delta E_{\mathrm{MM}}$ (subsystem) was found as $6 \mathrm{eV}$ (with a standard deviation of $2 \mathrm{eV}$ ). While reflecting a rough estimate, this is still sufficient for the binary question of endothermic/ exothermic proton transfer. If exothermic, proton transfer was typically found as favored by more than $3 \mathrm{eV}$.

\section{REFERENCES}

1. Munch E, Launey ME, Alsem DH et al. (2008) Tough, bio-inspired hybrid materials. Science 322(5907): 1516-1520.

2. Mao LB, Gao HL, Yao HB et al. (2016) Synthetic nacre by predesigned matrix-directed mineralization. Science 354(6308): 107-110.

3. Yao HB, Ge J, Mao LB, Yan YX and Yu SH (2014) 25th anniversary article: Artificial carbonate nanocrystals and layered structural nanocomposites inspired by nacre: synthesis, fabrication and applications. Advanced Materials 26(1): 163-187.

4. Gao HL, Chen SM, Mao LB et al. (2017) Mass production of bulk artificial nacre with excellent mechanical properties. Nature Communications 8(1): 287.
5. Tritschler U, Zlotnikov I, Zaslansky P et al. (2014) Hierarchically structured vanadium pentoxide-polymer hybrid materials. ACS Nano 8(5): 5089-5104.

6. Gehrke N, Nassif N, Pinna N et al. (2005) Retrosynthesis of nacre via amorphous precursor particles. Chemistry of Materials 17(26): 6514-6516.

7. Podsiadlo P, Liu Z, Paterson D, Messersmith PB and Kotov NA (2007) Fusion of seashell nacre and marine bioadhesive analogs: high-strength nanocomposite by layer-by-layer assembly of clay and L-3,4dihydroxyphenylalanine polymer. Advanced Materials 19(7): 949-955.

8. Wang J, Cheng Q and Tang Z (2012) Layered nanocomposites inspired by the structure and mechanical properties of nacre. Chemical Society Reviews 41(3): 1111-1129.

9. Tang Z, Kotov NA, Magonov S and Ozturk B (2003) Nanostructured artificial nacre. Nature Materials 2(6): 413-418.

10. Das P, Schipmann S, Malho JM et al. (2013) Facile access to largescale, self-assembled, nacre-inspired, high-performance materials with tunable nanoscale periodicities. ACS Applied Materials \& Interfaces 5(9): 3738-3747.

11. Morits M, Verho T, Sorvari J et al. (2017) Toughness and fracture properties in nacre-mimetic clay/polymer nanocomposites. Advanced Functional Materials 27(10): 1605378.

12. Das P, Malho JM, Rahimi K et al. (2015) Nacre-mimetics with synthetic nanoclays up to ultrahigh aspect ratios. Nature Communications 6: 5967.

13. Zhu B, Jasinski N, Benitez A et al. (2015) Hierarchical nacre mimetics with synergistic mechanical properties by control of molecular interactions in self-healing polymers. Angewandte Chemie International Edition 54(30): 8653-8657.

14. Studart AR (2014) Bioinspired ceramics: turning brittleness into toughness. Nature Materials 13(5): 433-435.

15. Helminger $M, W u B$, Kollmann T et al. (2014) Synthesis and characterization of gelatin-based magnetic hydrogels. Advanced Functional Materials 24(21): 3187-3196.

16. Siglreitmeier M, Wu B, Kollmann T et al. (2015) Multifunctional layered magnetic composites. Beilstein Journal of Nanotechnology $\mathbf{6}$ : 134-148.

17. Debus C, Siglreitmeier M and Cölfen H (2018) Biopolymer-directed magnetic composites. In Biological Magnetic Materials and Applications (Matsunaga T, Tanaka T and Kisailus D (eds)). Springer, Singapore, pp. 175-199.

18. Erb RM, Libanori R, Rothfuchs $N$ and Studart AR (2012) Composites reinforced in three dimensions by using low magnetic fields. Science 335(6065): 199-204.

19. Bouville F, Maire E, Meille S et al. (2014) Strong, tough and stiff bioinspired ceramics from brittle constituents. Nature Materials 13(5): 508-514.

20. Finnemore A, Cunha P, Shean T et al. (2012) Biomimetic layer-bylayer assembly of artificial nacre. Nature Communications 3: 966.

21. Currey JD (1977) Mechanical properties of mother of pearl in tension. Proceedings of the Royal Society Series B - Biological Sciences 196(1125): 443-436. 
Bioinspired, Biomimetic and Nanobiomaterials Volume 8 Issue BBN1
Bioinspired multifunctional layered

magnetic hybrid materials

Debus, Wu, Kollmann et al.
22. Weaver JC, Wang QQ, Miserez A et al. (2010) Analysis of an ultra hard magnetic biomineral in chiton radular teeth. Materials Today 13(1-2): 42-52.

23. Grunenfelder LK, de Obaldia EE, Wang Q et al. (2014) Stress and damage mitigation from oriented nanostructures within the radular teeth of Cryptochiton stelleri. Advanced Functional Materials 24(39): 6093-6104.

24. Escobar de Obaldia E, Herrera S, Grunenfelder LK, Kisailus D and Zavattieri P (2016) Competing mechanisms in the wear resistance behavior of biomineralized rod-like microstructures. Journal of the Mechanics and Physics of Solids 96: 511-534.

25. Brooker LR and Shaw JA (2012) The chiton radula: a unique model for biomineralization studies. In Advanced Topics in Biomineralization (Seto J (ed.)). InTech, Rijeka, Croatia, pp. 65-84.

26. Lee AP, Brooker LR, Macey DJ, van Bronswijk W and Webb J (2000) Apatite mineralization in teeth of the chiton Acanthopleura echinata. Calcified Tissue International 67(5): 408-415.

27. He MY, Evans AG and Hutchinson JW (1994) Crack deflection at an interface between dissimilar elastic materials: role of residual stresses. International Journal of Solids and Structures 31(24): 3443-3455.

28. Nemoto M, Wang Q, Li D et al. (2012) Proteomic analysis from the mineralized radular teeth of the giant Pacific chiton, Cryptochiton stelleri (Mollusca). Proteomics 12(18): 2890-2894.

29. Wang Q, Nemoto M, Li D et al. (2013) Phase transformations and structural developments in the radular teeth of Cryptochiton stelleri. Advanced Functional Materials 23(23): 2908-2917.

30. de Obaldia EE, Jeong C, Grunenfelder LK, Kisailus D and Zavattieri $P$ (2015) Analysis of the mechanical response of biomimetic materials with highly oriented microstructures through 3D printing, mechanical testing and modeling. Journal of the Mechanical Behavior of Biomedical Materials 48: 70-85.

31. Liddiard KJ, Hockridge JG, Macey DJ, Webb J and Bronswijk W (2004) Mineralisation in the teeth of the limpets Patelloida alticostata and Scutellastra laticostata (Mollusca: Patellogastropoda). Molluscan Research 24(1): 21-31.

32. van der Wal P (1989) Structural and material design of mature mineralized radula teeth of Patella vulgata (Gastropoda). Journal of Ultrastructure and Molecular Structure Research 102(2): 147-161.

33. Barber AH, Lu D and Pugno NM (2015) Extreme strength observed in limpet teeth. Journal of the Royal Society Interface 12(105): 20141326.

34. Faivre D and Godec TU (2015) From bacteria to mollusks: the principles underlying the biomineralization of iron oxide materials Angewandte Chemie International Edition 54(16): 4728-4747.

35. Dunin-Borkowski RE, McCartney MR, Frankel RB et al. (1998) Magnetic microstructure of magnetotactic bacteria by electron holography. Science 282(5395): 1868-1870.

36. Faivre D and Schüler D (2008) Magnetotactic bacteria and magnetosomes. Chemical Reviews 108(11): 4875-4898.

37. Faivre D (2015) Formation of magnetic nanoparticle chains in bacterial systems. MRS Bulletin 40(6): 509-515.

38. Bennet M, Bertinetti L, Neely RK et al. (2015) Biologically controlled synthesis and assembly of magnetite nanoparticles. Faraday Discussions 181: 71-83.

39. Mann S (2001) Biomineralization : Principles and Concepts in Bioinorganic Materials Chemistry. Oxford University Press, New York, NY, USA.

40. Meldrum FC and Colfen H (2008) Controlling mineral morphologies and structures in biological and synthetic systems. Chemical Reviews 108(11): 4332-4432.

41. Xu AW, Ma Y and Colfen H (2007) Biomimetic mineralization. Journal of Materials Chemistry 17(5): 415-449.

42. Cai G, Guo X and Yu S (2008) Polymer controlled biomimetic mineralization. Progress in Chemistry 20(0708): 1001-1014.
43. Ding C, Chen Z and Li J (2017) From molecules to macrostructures: recent development of bioinspired hard tissue repair. Biomaterials Science 5(8): 1435-1449.

44. Kim S and Park CB (2013) Bio-inspired synthesis of minerals for energy, environment, and medicinal applications. Advanced Functional Materials 23(1): 10-25.

45. Cölfen H (2007) Bio-inspired mineralization using hydrophilic polymers. In Biomineralization II: Mineralization Using Synthetic Polymers and Templates (Naka K (ed.)). Springer, Berlin, Germany, pp. 1-77.

46. Li L, Connors MJ, Kolle M et al. (2015) Multifunctionality of chiton biomineralized armor with an integrated visual system. Science 350(6263): 952-956.

47. Siglreitmeier M (2015) Multifunctional Layered Magnetic Composites. PhD thesis, University of Konstanz, Konstanz, Germany.

48. Addadi L, Joester D, Nudelman F and Weiner S (2006) Mollusk shell formation: a source of new concepts for understanding biomineralization processes. Chemistry - a European Journal 12(4) 981-987.

49. Goya GF, Berquó TS, Fonseca FC and Morales MP (2003) Static and dynamic magnetic properties of spherical magnetite nanoparticles. Journal of Applied Physics 94(5): 3520-3528.

50. Giraldez de Luis I, Garrido MA, Gomez-del Rio T and Ceballos L (2010) Comparison of the mechanical properties of dentin and enamel determined by different nanoindentation techniques: conventional method and continuous stiffness measurement. Boletin de la Sociedad Espaniola de Ceracmica y Vidrio 49(3): 177-182.

51. Libanori R, Erb RM and Studart AR (2013) Mechanics of plateletreinforced composites assembled using mechanical and magnetic stimuli. ACS Applied Materials \& Interfaces 5(21): 10794-10805.

52. Mayer C, Yang LW, Singh SS et al. (2016) Orientation dependence of indentation behavior in Al-SiC nanolaminate composites. Materials Letters 168: 129-133.

53. Heiss A, Jahnen-Dechent W, Endo H and Schwahn D (2007) Structural dynamics of a colloidal protein-mineral complex bestowing on calcium phosphate a high solubility in biological fluids. Biointerphases 2(1): 16-20.

54. Pipich V, Balz M, Wolf SE, Tremel W and Schwahn D (2008) Nucleation and growth of $\mathrm{CaCO}_{3}$ mediated by the egg-white protein ovalbumin: a time-resolved in situ study using small-angle neutron scattering. Journal of the American Chemical Society 130(21): 6879-6892.

55. Wu B, Siglreitmeier M, Debus C et al. (2018) Ionic dependence of gelatin hydrogel architecture explored using small and very small angle neutron scattering technique. Macromolecular Bioscience 18(6): e1800018.

56. Bressler I, Pauw BR and Thunemann AF (2015) McSAS: software for the retrieval of model parameter distributions from scattering patterns. Journal of Applied Crystallography 48: 962-969.

57. Sugimoto T and Matijević E (1980) Formation of uniform spherical magnetite particles by crystallization from ferrous hydroxide gels. Journal of Colloid and Interface Science 74(1): 227-243.

58. Weiner S, Traub W and Parker SB (1984) Macromolecules in mollusc shells and their functions in biomineralization [and discussion]. Philosophical Transactions of the Royal Society of London B: Biological Sciences 304(1121): 425-434.

59. Weiner S and Traub W (1980) X-ray diffraction study of the insoluble organic matrix of mollusk shells. FEBS Letters 111(2): 311-316.

60. Li WL, Lu K and Walz JY (2012) Freeze casting of porous materials: review of critical factors in microstructure evolution. International Materials Reviews 57(1): 37-60.

61. Anwar J and Zahn D (2011) Uncovering molecular processes in crystal nucleation and growth by using molecular simulation. Angewandte Chemie International Edition 50(9): 1996-2013.

62. Tlatlik H, Simon P, Kawska A, Zahn D and Kniep R (2006) Biomimetic fluorapatite-gelatine nanocomposites: pre-structuring of gelatine matrices by ion impregnation and its effect on form 
Bioinspired, Biomimetic and Nanobiomaterials Volume 8 Issue BBN1
Bioinspired multifunctional layered

magnetic hybrid materials

Debus, Wu, Kollmann et al. development. Angewandte Chemie International Edition 45(12): 1905-1910.

63. Kawska A, Duchstein P, Hochrein O and Zahn D (2008) Atomistic mechanisms of $\mathrm{ZnO}$ aggregation from ethanolic solution: ion association, proton transfer, and self-organization. Nano Letters $\mathbf{8 ( 8 )}$ 2336-2340.

64. Kotlarchyk M and Chen SH (1983) Analysis of small-angle neutronscattering spectra from polydisperse interacting colloids. Journal of Chemical Physics 79(5): 2461-2469.

65. López T, Méndez J, Zamudio T and Villa M (1992) Spectroscopic study of sol-gel silica doped with iron ions. Materials Chemistry and Physics 30(3): 161-167.

66. Waite JH, Lichtenegger HC, Stucky GD and Hansma P (2004) Exploring molecular and mechanical gradients in structural bioscaffolds. Biochemistry 43(24): 7653-7662.

67. Xu J, McCarthy SP, Gross RA and Kaplan DL (1996) Chitosan film acylation and effects on biodegradability. Macromolecules 29(10): 3436-3440.

68. Oliver WC and Pharr GM (1992) An improved technique for determining hardness and elastic modulus using load and displacement sensing indentation experiments. Journal of Materials Research 7(6): 1564-1583.

69. Li X and Bhushan B (2002) A review of nanoindentation continuous stiffness measurement technique and its applications. Materials Characterization 48(1): 11-36.

70. Feoktystov AV, Frielinghaus H, Di ZY et al. (2015) KWS-1 highresolution small-angle neutron scattering instrument at JCNS: current state. Journal of Applied Crystallography 48: 61-70.
71. Pipich V and Fu Z (2015) KWS-3: very small angle scattering diffractometer with focusing mirror. Journal of Large-scale Research Facilities 1: A31.

72. Pipich V (2015) http://www.qtikws.de (accessed 02/12/2015).

73. Kline SR (2006) Reduction and analysis of SANS and USANS data using IGOR Pro. Journal of Applied Crystallography 39: 895-900.

74. Wang J, Wolf RM, Caldwell JW, Kollman PA and Case DA (2004) Development and testing of a general Amber force field. Journal of Computational Chemistry 25(9): 1157-1174.

75. Bayly Cl, Cieplak P, Cornell W and Kollman PA (1993) A well-behaved electrostatic potential based method using charge restraints for deriving atomic charges: the RESP model. Journal of Physical Chemistry 97(40): 10269-10280.

76. Lorentz HA (1881) Ueber die Anwendung des Satzes vom Virial in der kinetischen Theorie der Gase. Annalen der Physik 248(1): 127-136 (in German).

77. Berthelot D (1898) Sur le mélange des gaz. Comptes rendus hebdomadaires des séances de l'Académie des Sciences 126: 1703-1855 (in German).

78. Allen FH, Kennard O, Watson DG et al. (1987) Tables of bond lengths determined by X-ray and neutron diffraction: part 1 bond lengths in organic compounds. Journal of the Chemical Society, Perkin Transactions 2 1987(12): S1-S19.

79. Harmony MD, Laurie VW, Kuczkowski RL et al. (1979) Molecular structures of gas-phase polyatomic molecules determined by spectroscopic methods. Journal of Physical and Chemical Reference Data 8(3): 619-721.

\section{How can you contribute?}

To discuss this paper, please submit up to 500 words to the journal office at journals@ice.org.uk. Your contribution will be forwarded to the author(s) for a reply and, if considered appropriate by the editor-in-chief, it will be published as a discussion in a future issue of the journal.

ICE Science journals rely entirely on contributions from the field of materials science and engineering. Information about how to submit your paper online is available at www.icevirtuallibrary.com/page/authors, where you will also find detailed author guidelines. 